\title{
Review
}

\section{Temperature Sensors Based on Organic Field-Effect Transistors}

\author{
John Polena, Daniel Afzal, Jenner H. L. Ngai and Yuning Li *(D)
}

check for

updates

Citation: Polena, J.; Afzal, D.; Ngai, J.H.L.; Li, Y. Temperature Sensors

Based on Organic Field-Effect

Transistors. Chemosensors 2022, 10, 12.

https://doi.org/10.3390/

chemosensors10010012

Academic Editor: Filippo Giubileo

Received: 5 December 2021

Accepted: 22 December 2021

Published: 27 December 2021

Publisher's Note: MDPI stays neutral with regard to jurisdictional claims in published maps and institutional affiliations.

Copyright: (C) 2021 by the authors. Licensee MDPI, Basel, Switzerland. This article is an open access article distributed under the terms and conditions of the Creative Commons Attribution (CC BY) license (https:// creativecommons.org/licenses/by/ $4.0 /)$.

\author{
Department of Chemical Engineering, Waterloo Institute for Nanotechnology (WIN), University of Waterloo, \\ Waterloo, ON N2L 3G1, Canada; jpolena@uwaterloo.ca (J.P.); d2afzal@uwaterloo.ca (D.A.); \\ jenner.ngai@uwaterloo.ca (J.H.L.N.) \\ * Correspondence: yuning.li@uwaterloo.ca; Tel.: +1-519-888-4567 (ext. 31105)
}

\begin{abstract}
The rapid growth of wearable electronics, Internet of Things, smart packaging, and advanced healthcare technologies demand a large number of flexible, thin, lightweight, and ultralowcost sensors. The accurate and precise determination of temperature in a narrow range $\left(\sim 0-50^{\circ} \mathrm{C}\right)$ around ambient temperatures and near-body temperatures is critical for most of these applications. Temperature sensors based on organic field-effect transistors (OFETs) have the advantages of low manufacturing cost, excellent mechanical flexibility, easy integration with other devices, low crosssensitivity, and multi-stimuli detectability and, therefore, are very suitable for the above applications. This article provides a timely overview of research progress in the development of OFET-based temperature sensors. First, the working mechanism of OFETs, the fundamental theories of charge transport in organic semiconductors, and common types of OFET temperature sensors based on the sensing element are briefly introduced. Next, notable advances in the development of OFET temperature sensors using small-molecule and polymer semiconductors are discussed separately. Finally, the progress of OFET temperature sensors is summarized, and the challenges associated with OFET temperature sensors and the perspectives of research directions in this field are presented.
\end{abstract}

Keywords: temperature sensor; sensitivity; thermal coefficient of resistance (TCR); organic field effect transistor; organic thin film transistor; organic semiconductor; dielectric; thermistor; capacitor

\section{Introduction}

Organic field-effect transistors (OFETs) or organic thin-film transistors (OTFTs) use organic semiconductors (OSCs) including covalent organic frameworks (COFs) and metalorganic frameworks (MOFs) as active channel materials, which enables the high-speed fabrication of electronic products on flexible plastic substrates under mild conditions at an ultralow cost [1-6]. OFETs have a wide range of applications, such as flexible displays, smart labels, intelligent packaging, various types of sensors, wearable electronics, implantable electronics, etc. OFET-based sensors, in particular, are ultralow in cost and can be integrated with other electronics as on-chip sensors, making them an excellent fit for the rapidly growing Internet of Things (IoT) technology, wearable electronics, and healthcare applications [7-11].

Temperature determination is one of the most common applications for modern-day sensors. The field of medicine has a demand for high functioning temperature sensors to be used in vital sign monitoring [12-14]. Furthermore, recent developments towards designing artificial skin, or electronic skin (e-skin), require accurate temperature monitoring as well as flexible systems with spatial resolution for practical application $[15,16]$. Temperature determination is also imperative for monitoring other physical parameters such as pressure, humidity, and gas concentration, which can have a temperature dependence and cannot be accurately determined without adjusting for temperature fluctuation [17].

Similar to a conventional metal oxide semiconductor field-effect transistor (MOSFET), an OFET device consists of three electrodes (source, drain, and gate), a dielectric layer, and an organic semiconductor layer. Figure 1 shows the four common structures of OFETs, 
bottom-gate top-contact (BGTC), bottom-gate bottom-contact (BGBC), top-gate top-contact (TGTC), and top-gate bottom-contact (TGBC). The OFET current-voltage characteristics are schematically shown in Figure 1e. The output characteristics illustrate the changes of the drain current $\left(I_{\mathrm{DS}}\right)$ with the drain voltage $\left(V_{\mathrm{DS}}\right)$ at different gate voltages $\left(V_{\mathrm{GS}}\right)$. At a very low $V_{\mathrm{DS}}$, the $I_{\mathrm{DS}}-V_{\mathrm{DS}}$ relationship is ohmic (linear), and this region is called the linear regime (or region). As $V_{\mathrm{DS}}$ increases, $I_{\mathrm{DS}}$ increases at a slower rate, and the $I-V$ curve becomes non-linear. After $V_{\mathrm{DS}}$ reaches a certain point, where $V_{\mathrm{DS}}=V_{\mathrm{GS}}-V_{\mathrm{T}}, I_{\mathrm{DS}}$ becomes independent of $V_{\mathrm{DS}}$, and the channel is called pinched off. $V_{\mathrm{T}}$ here is the threshold voltage, which is the minimum gate voltage required to fill the charge traps at the channel. The region where $V_{\mathrm{DS}}>V_{\mathrm{GS}}-V_{\mathrm{T}}$ is called the saturation regime. The changes of $I_{\mathrm{DS}}$ with $V_{\mathrm{GS}}$ at a fixed $V_{\mathrm{DS}}$ are the transfer characteristics. In the linear regime $\left(V_{\mathrm{DS}}<<V_{\mathrm{GS}}\right), I_{\mathrm{DS}}$ and $V_{\mathrm{GS}}$ have the following relationship $[18,19]$ :

$$
I_{\mathrm{DS}}=\frac{W}{L} \mu_{\text {lin }} C_{\mathrm{i}}\left(V_{\mathrm{GS}}-V_{\mathrm{T}}\right) V_{\mathrm{DS}},
$$

where $W$ is the channel width, $L$ is the channel length, $\mu_{\text {lin }}$ is the field effect mobility in the linear regime, and $C_{\mathrm{i}}$ is the capacitance of the dielectric layer.

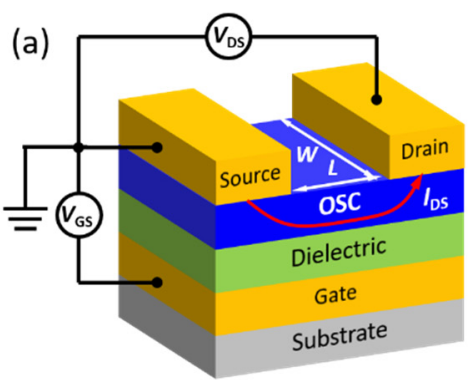

(b)

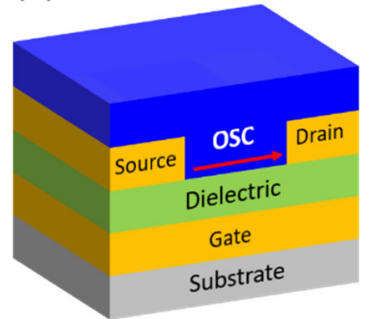

(c)

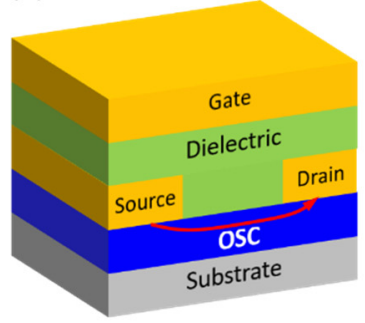

(d)

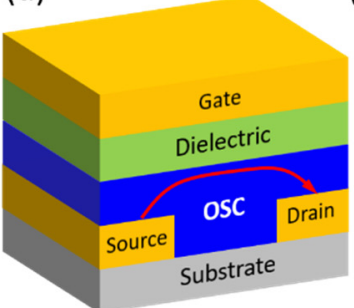

(e)

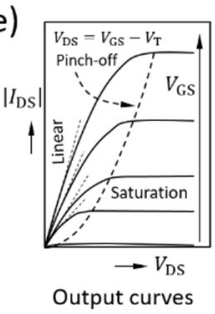

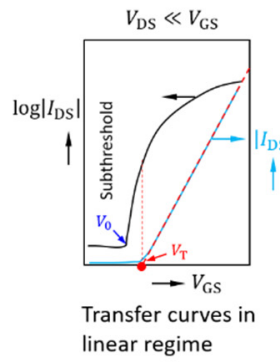

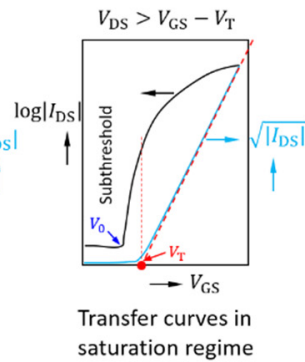

Figure 1. Four common OFET architectures: (a) bottom-gate top-contact (BGTC), (b) bottom-gate bottom-contact (BGBC), (c) top-gate top-contact (TGTC), and (d) top-gate bottom-contact (TGBC). Schematic output characteristics and transfer characteristics in the linear and saturation regimes of an OFET device are shown in (e), where $V_{\mathrm{DS}}$ is the drain voltage, $I_{\mathrm{DS}}$ is the drain current, $V_{\mathrm{GS}}$ is the gate voltage, $V_{\mathrm{T}}$ is the threshold (gate) voltage, and $V_{0}$ is the onset (gate) voltage. The red arrows in (a-d) indicate the current flow in the channel.

From the $I_{\mathrm{DS}}-V_{\mathrm{GS}}$ curve, $\mu_{\text {lin }}$ can be extracted:

$$
\mu_{\text {lin }}=\frac{\partial I_{\mathrm{DS}}}{\partial V_{\mathrm{GS}}} \frac{L}{W C_{\mathrm{i}} V_{\mathrm{DS}}}
$$

In the saturation regime $\left(V_{\mathrm{DS}}>V_{\mathrm{GS}}-V_{\mathrm{T}}\right), I_{\mathrm{DS}}$ and $V_{\mathrm{GS}}$ have the following relationship:

$$
I_{\mathrm{DS}, \mathrm{sat}}=\frac{W}{2 L} \mu_{\mathrm{sat}} C_{\mathrm{i}}\left(V_{\mathrm{GS}}-V_{\mathrm{T}}\right)^{2}
$$

where $I_{\mathrm{DS} \text {, sat }}$ and $\mu_{\mathrm{sat}}$ are the drain current and mobility in the saturation regime, respectively. $\mu_{\text {sat }}$ can be calculated from the saturation transfer curves using the following equation:

$$
\mu_{\mathrm{sat}}=\frac{\partial I_{\mathrm{DS}, \mathrm{sat}}}{\partial V_{\mathrm{GS}}} \frac{L}{W C_{\mathrm{i}}\left(V_{\mathrm{GS}}-V_{\mathrm{T}}\right)}
$$


Similar to the conventional resistor-type temperature sensor, or thermistor, the sensitivity of the OFET sensor can be described using the thermal coefficient of resistance (TCR), which can be calculated by

$$
T C R=\frac{R-R_{0}}{R_{0}} \times \frac{1}{\Delta T} \times 100 \%
$$

where $R$ is the resistance of the channel at a given temperature, $R_{0}$ is the resistance of the channel at a known reference temperature, and $\Delta T$ is the difference between the sensing and reference temperatures [20]. For OFET devices, the ratio of $\frac{R-R_{0}}{R_{0}}$ can be easily calculated using the variation of $I_{\mathrm{DS}}$ with the temperature at constant $V_{\mathrm{GS}}$ and $V_{\mathrm{DS}}, \frac{I_{\mathrm{DS}}-I_{\mathrm{DS}, 0}}{I_{\mathrm{DS}, 0}}$.

The conventional two-electrode resistor-type temperature sensor can only give one independent output parameter, such as current or voltage. The change in current or voltage may be induced by interfering stimuli such as pressure and humidity, causing cross-sensitivity issues. On the other hand, the OFET temperature sensor can provide numerous parameters, such as $I_{\mathrm{DS}}$ and $V_{\mathrm{DS}}$ (in different regimes), onset voltage $\left(V_{0}\right)$, threshold voltage $\left(V_{\mathrm{T}}\right)$, and mobility $(\mu)[18,19]$. This multi-parameter sensing capability enables OFET temperature sensors to distinguish temperature-induced parameter changes from pressure, light, chemical substances, and other stimuli-induced changes, providing high selectivity and reliability of multi-functional sensing [21,22].

Organic materials are composed of molecules as the basic building blocks, which are made of carbon, oxygen, hydrogen, nitrogen, and other elements. The constituent atoms in an organic molecule are strongly held with covalent bonds between atoms by sharing the valence electrons. Therefore, most organic materials are insulators because valence electrons are highly localized. A characteristic of organic semiconductors is that their skeleton has an extended $\pi$-conjugated system, usually composed of alternating $C-C$ and $\mathrm{C}=\mathrm{C}$ bonds. The overlapping (or hybridization) of the molecular orbitals forms an extended highest occupied molecular orbital (HOMO) and a lowest unoccupied molecular orbital (LUMO), where the injected holes (in HOMO) and electrons (in LUMO) can move relatively easily. As the molecular size increases, such as in the case of high molecular weight polymers, long-range $\pi$ conjugation results in a band-like structure with a small band gap $(<3 \mathrm{eV})$ between HOMO and LUMO, similar to typical inorganic semiconductors. However, organic molecules are held together by weak van der Waals forces or London dispersion forces to form a solid, so the intermolecular distance is quite large, usually 0.3-0.4 nm. This makes intermolecular charge transport more difficult than intramolecular charge transport. Organic molecules are much larger than the spherical constituent atoms and ions in inorganic materials and have more complex geometric shapes. Therefore, most organic semiconductors are disordered (polycrystalline or amorphous), which makes charge transport in organic semiconductors even more difficult and highly dependent on the processing conditions of the material. As a result, the charge transport mechanism in organic semiconductors is extremely complicated and has been a subject of extensive study since its discovery.

Numerous charge transport models have been proposed for organic semiconductors, including multiple trapping and release (MTR), variable range hopping (VRH), band-like transport, percolation model, and Gaussian disorder model (GDM), according to the type of material, degree of crystallinity, temperature range, applied voltage, etc. [23-27].

As shown in Figure 2, the charge carrier mobility of organic semiconductors may increase or decrease with increasing temperature, depending on the model, which results in a decrease in resistance (a negative temperature coefficient, NTC) or an increase in resistance (a positive temperature coefficient, PTC), respectively. Since $I_{\mathrm{DS}}$ in the linear (Equation (1)) or saturated (Equation (2)) regime is a function of the carrier mobility of the organic semiconductor channel, it can be used as an output signal to detect the temperature change. MTR and VRH models, in which mobility increases with temperature, are most widely used in polycrystalline or amorphous organic semiconductors. Some highly crystalline small molecules [28-31] and polymers [32-35] have been found to follow a "band-like" 
transport model around room temperature, in which mobility decreases with temperature. The mobility of organic semiconductors is also field dependent [23,24], and the field-effect mobility is often strongly dependent on the gate voltage [27]. Consequently, the sensitivity of an OFET temperature sensor may also be influenced by the voltage applied.

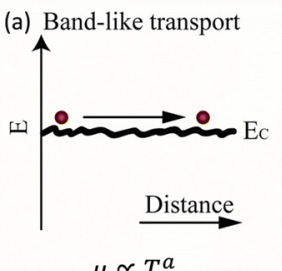

$\mu \propto T^{a}$

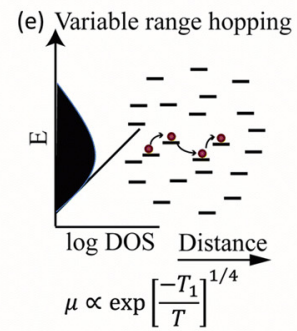

(i) Charge transfer (Marcus)

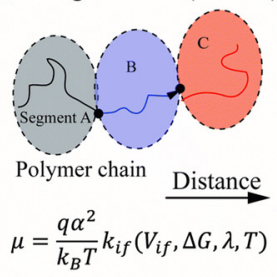

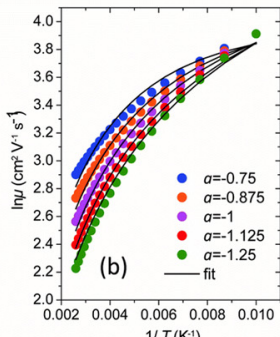
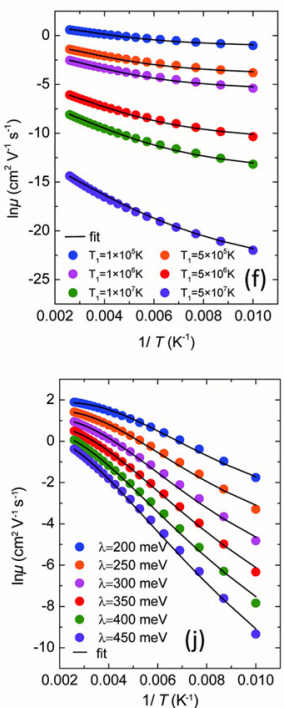

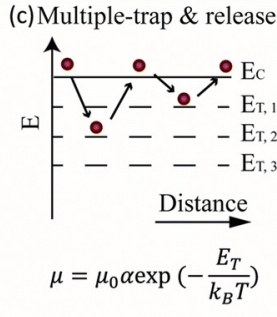

(g)

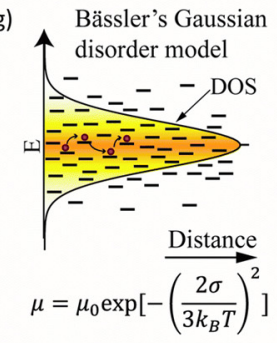

(k) Nuclear tunneling

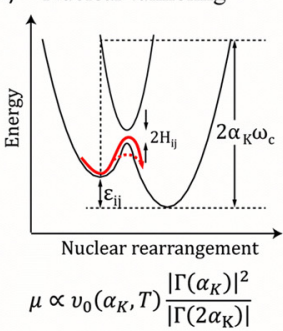

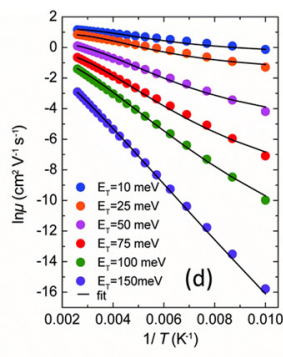
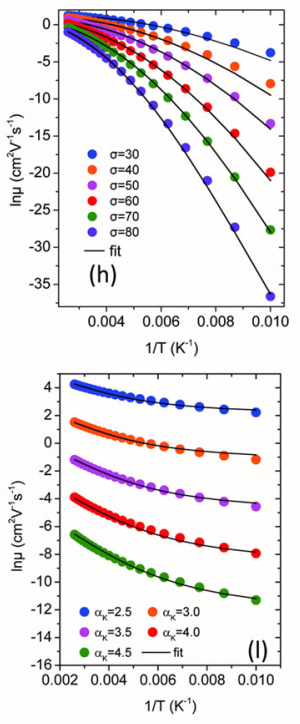

Figure 2. Various charge transport mechanisms for organic semiconductors (a) Band-like transport and (b) its corresponding mobility-temperature relationship; (c) Multiple-trap and release and (d) its corresponding mobility-temperature relationship; (e) Variable range hopping and (f) its corresponding mobility-temperature relationship; (g) Bässler's Gaussian disorder model and (h) its corresponding mobility-temperature relationship; (i) Charge transfer (Marcus) and (j) its corresponding mobility-temperature relationship; (k) Nuclear tunneling and (1) its corresponding mobility-temperature relationship. Reproduced with permission from [36] Royal Society of Chemistry, 2017.

Deep charge carrier traps in the organic semiconductor or the dielectric layer near their interface must be filled before a significant current flows in the channel; therefore, a larger number of deep traps leads to an increase in the threshold voltage $\left(V_{\mathrm{T}}\right)$ and the onset voltage $\left(V_{0}\right)[18,19,37]$. As temperature increases, some deep traps become shallow traps, resulting in a decrease in $V_{\mathrm{T}}$ and $V_{0}[36,37]$. Therefore, $V_{\mathrm{T}}$ or $V_{0}$ can be directly used as a parameter to detect the temperature change. As shown in Equations (1) and (2) and Figure $1, I_{\mathrm{DS}}$ in the subthreshold region is also significantly dependent on the threshold voltage $V_{\mathrm{T}}$ and hence on the temperature.

$I_{\mathrm{DS}}$ is proportional to the capacitance $\left(C_{\mathrm{i}}\right)$ of the dielectric layer (Equations (1) and (2)), while $C_{\mathrm{i}}$ is proportional to the relative permittivity or dielectric constant $(k)$ of the dielectric material: $C_{i}=k C_{0}$, where $C_{0}$ is the vacuum capacitance. The properties of the dielectric layer material, such as dielectric constant and surface trap density, also have a profound impact on $I_{\mathrm{DS}}, V_{\mathrm{T}}$, and even mobility [38]. Therefore, a dielectric material whose properties change dramatically with temperature can induce significant changes in OFET parameters and thus can be used as a sensor element. 
Instead of using an OFET component as the sensing element, a separate temperaturesensing element can be integrated with OFET to form an OFET temperature sensor system. For instance, a thermistor is often connected to the gate electrode of the OFET to modulate the OFET $I-V$ characteristics and achieve more sensitive and reliable temperature sensing. Similarly, a capacitor or diode unit can be connected to the OFET as the temperature sensing element to overcome the low sensitivity and complicated temperature response of the OFET active layer. Various representative OFET-based temperature sensors with different sensing elements are schematically shown in Figure 3.

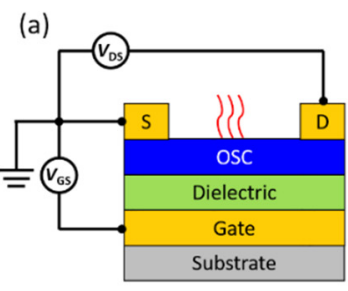

(d)

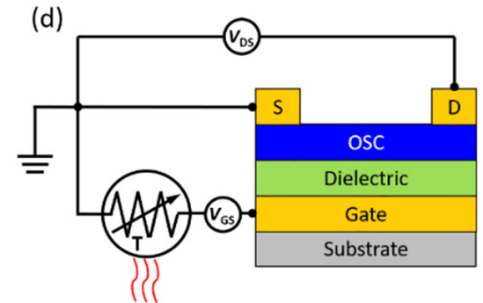

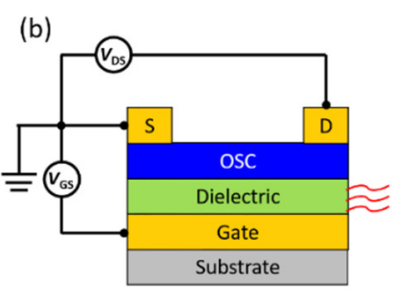
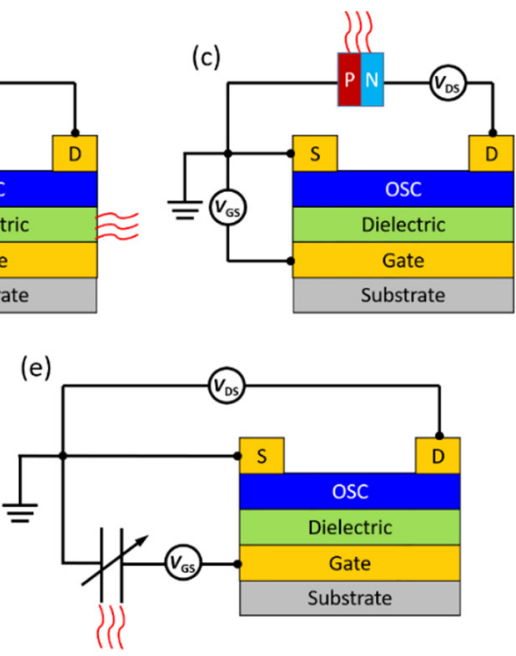

Figure 3. OFET-based temperature sensors with different sensing elements: (a) OFET active layer [39]; (b) dielectric layer [40]; (c) separate diode (shows the diode direction of the p-channel OFET) [41]; (d) separate thermistor [42]; (e) separate capacitor [43].

This review aims to introduce and analyze representative studies on OFET temperature sensing devices in terms of materials, device design, and sensing performance. We discuss small-molecule and polymer semiconductors separately, the structures of which are shown in Figure 4. We have classified the device structures by the sensing elements, OFET active layer, dielectric layer, separate thermistor, and other types of sensing elements. Finally, we summarize our findings and provide future prospects on OFET-based temperature sensors. The purpose of this article is to provide readers with a better understanding of the status quo and the challenges that must be overcome before OFET-based temperature sensors can become a viable sensor technology.

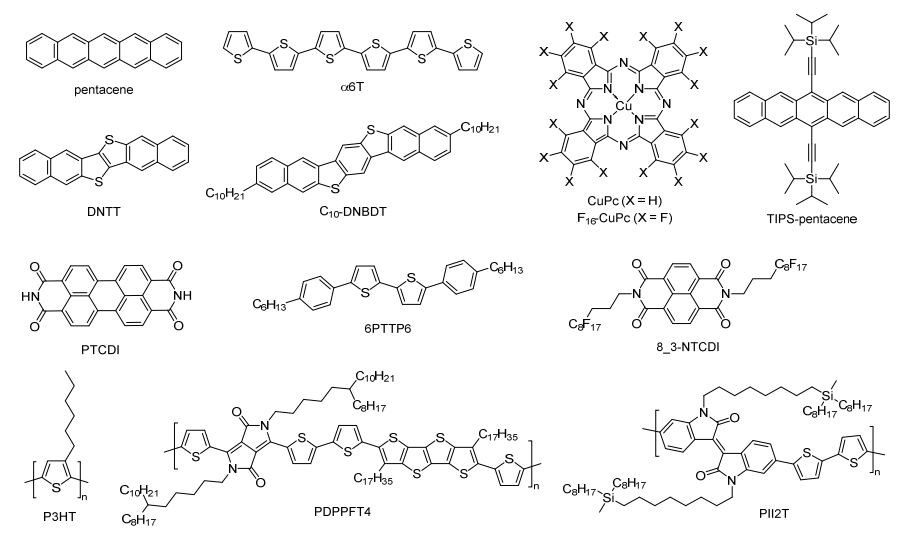

Figure 4. Chemical structures of small-molecule and polymeric semiconductors used for OFET temperature sensors. 


\section{Small-Molecule Semiconductor-Based OFET Temperature Sensors}

Organic small-molecule semiconductors have the advantages of straightforward synthesis, higher purity, and higher charge carrier mobility compared to their polymer counterparts [44-47]. OFETs based on small-molecule semiconductors have been extensively studied as sensors for various applications such as gas sensor, chemical sensors, biosensors, pressure sensors, etc. [48-50]. However, there is a scarcity of research publications on smallmolecule-based OFET temperature sensors, presumably due to some of the challenges that will be discussed in this review. Nonetheless, promising results have been obtained through efforts made in the improved materials processing and device design. This section will introduce and discuss small-molecule OFET temperature sensors based on the classification of temperature sensing elements: organic semiconductor channel layer, dielectric layer, separate thermistor, and other types.

\subsection{OFET Semiconductor Channel as Sensing Element}

Pentacene is one of the most commonly used semiconducting layers in OFET devices for various applications [51-54]. Jung et al. report an OTFT temperature sensor using pentacene as the semiconducting layer on a flexible polyethylene naphthalate (PEN) film for administering point-of-care diagnoses [39]. A $50 \mathrm{~nm}$ pentacene film was deposited on top of a polyvinylphenol (PVP) gate dielectric. When the device is measured between 0 and $80^{\circ} \mathrm{C}$, the $I_{\mathrm{DS}}$ increases with increasing temperature. This $I_{\mathrm{DS}}$ modulation is mainly due to the positive shift of the $V_{\mathrm{T}}$, so the most significant increase in current is observed in the subthreshold region with a linear increase from $\sim 10^{-10} \mathrm{~A}$ at $0{ }^{\circ} \mathrm{C}$ to $\sim 10^{-8} \mathrm{~A}$ at $80^{\circ} \mathrm{C}$.

The same group observed a similar linear $I_{\mathrm{DS}}-T$ dependence in the subthreshold region within the range of 0 to $180^{\circ} \mathrm{C}$ for a temperature sensor based on pentacene OTFT on a $\mathrm{SiO}_{2} / \mathrm{Si}$ substrate protected by a polyvinyl alcohol (PVA) mask [55]. $\mathrm{I}_{\mathrm{DS}}$ in the subthreshold region increases by almost four orders of magnitude with an increase in temperature from 0 to $180^{\circ} \mathrm{C}$. However, a lower $V_{\mathrm{T}}$ is required to achieve better sensitivity at the expense of $I_{\mathrm{DS}}-T$ linearity. It was found that $\mu_{\mathrm{sat}}$ in the saturation region increases with temperature in the relatively low temperature range of 0 to $60^{\circ} \mathrm{C}$ due to the thermally activated hopping transport, which agrees with the trend in the similar temperature range $\left(-13\right.$ to $\left.67^{\circ} \mathrm{C}\right)$ observed by Kawakami et al. [56]. The activation energy $\left(E_{\mathrm{a}}\right)$ obtained with an Arrhenius fit is $66 \mathrm{meV}$, indicating a weak dependence of $\mu$ on temperature. In the higher temperature range of 60 to $180^{\circ} \mathrm{C}, \mu$ decreases due to the dominance of carrier scattering at elevated temperatures. As a result, $I_{\mathrm{DS} \text {, sat }}$ increases slightly with temperature in the range of 0 to $180^{\circ} \mathrm{C}$. The dramatic increase in subthreshold current $\left(I_{\mathrm{DS}, \text { sub }}\right)$ with increasing temperature is mainly due the positive shift of $V_{\mathrm{T}}$. However, $V_{\mathrm{T}}$ is affected by the charge traps at the dielectric/semiconductor interface, bias stress, moisture, oxygen, morphology of the semiconductor layer, etc., so it is difficult to use the $I_{\mathrm{DS}, \text { sub }}$ as a sensor output in practical applications. Therefore, using the more reliable $I_{\mathrm{DS}}$ in the saturation region is preferred. However, as previously mentioned, the $I_{\mathrm{DS}}$ in the saturation region has a weak dependence on temperature, making it challenging to use as the sensor output.

Copper phthalocyamine $(\mathrm{CuPc})$ and fluorinated copper phthalocyanine $\left(\mathrm{F}_{16} \mathrm{CuPc}\right)$ are widely studied p-type and n-type small-molecule semiconductors for OFETs because of their good carrier mobility and environmental stability. $\mathrm{CuPc}$ and $\mathrm{F}_{16} \mathrm{CuPc}$ exhibit a weak dependence of $\mu_{\text {sat }}$ on temperature around room temperature, each having an $E_{\mathrm{a}}$ of 73 and $39 \mathrm{meV}[57,58]$, respectively, which are similar to that of pentacene $[55,56]$. Therefore, $I_{\mathrm{DS}}$ in the saturation region of OFETs based on these materials would also be weakly dependent on temperature and not suitable as the signal output of temperature sensors around room temperature. Consequently, Boileau et al. used the $V_{\mathrm{T}}$ response to the temperature of OFETs based on CuPc and $\mathrm{F}_{16}-\mathrm{CuPC}$ for DNA sensing [59]. The goal was to design an accurate temperature sensor working in the optimal temperature range $\left(40\right.$ to $\left.70{ }^{\circ} \mathrm{C}\right)$ where DNA binding occurs. The authors observed that the hole and electron mobilities $\left(\mu_{\mathrm{h}}\right.$ and $\left.\mu_{\mathrm{e}}\right)$ of $\mathrm{CuPc}$ and $\mathrm{F}_{16} \mathrm{CuPc}$ increase with temperature with coefficients of $1 \% /{ }^{\circ} \mathrm{C}$ and $0.1 \% /{ }^{\circ} \mathrm{C}$, respectively, in the temperature range of 25 to $90{ }^{\circ} \mathrm{C}$. On the other hand, the $V_{\mathrm{T}}$ changes 
significantly from $-7.6 \mathrm{~V}$ to $-1.8 \mathrm{~V}$ with a change rate of $0.11 \mathrm{~V} /{ }^{\circ} \mathrm{C}$ for $\mathrm{CuPc}$. For the n-type $\mathrm{F}_{16} \mathrm{CuPc}$-based OFET, the $V_{\mathrm{T}}$ changes to the negative direction from $-9.9 \mathrm{~V}$ to $-26.4 \mathrm{~V}$ with a charge rate of $-0.25 \mathrm{~V} /{ }^{\circ} \mathrm{C}$, indicating its better sensitivity than the $\mathrm{CuPc}$ device. The opposite $V_{\mathrm{T}}$ shift directions and different sensitivities observed for the two semiconductors may be due to their different carriers (holes and electrons) associated with different carrier traps at the interface between the semiconductor and the dielectric.

To improve the temperature sensitivity of $\mathrm{F}_{16} \mathrm{CuPc}$-based OFETs, Ye et al. developed an OFET device using a pn heterojunction layer of $\alpha$-sexithiophene $(\alpha 6 \mathrm{~T}) / \mathrm{F}_{16} \mathrm{CuPC}[60]$. Specifically, a layer of p-type semiconductor $\alpha 6 \mathrm{~T}$ was deposited on top of the $\mathrm{F}_{16} \mathrm{CuPC}$ semiconducting layer and the source/drain electrodes (Figure 5). It has been reported that the use of a pn heterojunction active channel layer in OFETs can realize ambipolar charge transport characteristics and/or improve charge carrier mobility [61-65]. In particular, the $V_{\mathrm{T}}$ is a function of the thickness of the top layer in the pn heterojunction [66], which may allow the use of $V_{\mathrm{T}}$ as the sensitivity parameter of the OFET temperature sensor in a more controllable manner. The authors found that when the thickness of the $\alpha 6 \mathrm{~T}$ layer increased from $0 \mathrm{~nm}$ to $\sim 5-7 \mathrm{~nm}, V_{\mathrm{T}}$ changed significantly from $23.13 \mathrm{~V}$ to $18.10 \mathrm{~V}$, and then stabilized. In the linear regime $\left(\left|V_{\mathrm{DS}}\right|<\left|V_{\mathrm{GS}}-V_{\mathrm{T}}\right|\right)$, the OFET with $\alpha 6 \mathrm{~T}(20 \mathrm{~nm}) / \mathrm{F}_{16} \mathrm{CuPC}$ $(50 \mathrm{~nm})$ displayed a linear $\log \left(I_{\mathrm{DS}}\right)$-versus- $T$ relationship: $\log \left(I_{D}\right)=k T+c_{0}$ in the temperature range of 100 to $300 \mathrm{~K}$ (Figure 5a), which is gate voltage dependent. The slope $k$ increases with $V_{\mathrm{GS}}$ first, reaching the maximum value of $0.11 \mathrm{dec} /{ }^{\circ} \mathrm{C}$ at $V_{\mathrm{GS}}=5 \mathrm{~V}(\operatorname{most}$ sensitive), and then drops rapidly with further increasing $V_{\mathrm{GS}}$ (Figure $5 \mathrm{~b}$ ). As shown in Figure $5 \mathrm{c}, \mu$ follows a thermally activated Arrhenius behaviour $\left(\mu \propto \exp \left(-E_{\mathrm{a}} / k_{\mathrm{B}} T\right)\right)$ with two distinct temperature ranges. The activation energy $E_{\mathrm{a}}$ is $40.1 \mathrm{meV}$ above $200 \mathrm{~K}$ and drops to $16.3 \mathrm{meV}$ in the lower temperature range of 100 to $200 \mathrm{~K}$. The device also showed linear temperature dependence of $V_{\mathrm{T}}$ with different slopes in the two temperature ranges (Figure $5 \mathrm{~d}$ ). In the range of 100 to $200 \mathrm{~K}$, the sensitivity $\left(\Delta V_{\mathrm{T}} / \Delta T\right)$ is $-0.90 \mathrm{~V} /{ }^{\circ} \mathrm{C}$, and between $200 \mathrm{~K}$ and $300 \mathrm{~K}$, the sensitivity is $-0.185 \mathrm{~V} /{ }^{\circ} \mathrm{C}$. These two regions are attributed to two different mechanisms dominating in each region. The charge transport in the lower temperature range is dominated by the MTR mechanism, while the charge transport in the higher temperature range is dominated by the thermal enhancement of the hopping transport or VRH. These sensitivities are higher than those of a previously reported OFET with a similar structure with only $\mathrm{F}_{16} \mathrm{CuPC}\left(-0.02 \mathrm{~V} /{ }^{\circ} \mathrm{C}\right)$ [58], indicating the beneficial effect of using a pn heterojunction structure to improve the sensitivity of the sensor.

An organic-inorganic hybrid perovskite-based ambipolar FET temperature sensor was reported by Haque et al. recently [67]. The active $\mathrm{MAPbI}_{3}$ layer is fabricated using a stoichiometric mixture of powdered methylammonium iodide (MAI) and lead iodide $\left(\mathrm{PbI}_{2}\right)$. The OTFT exhibited excellent air stability without the need for an encapsulation layer. The charge transport obeys the MTR mechanism where traps, mostly localized in the grain boundaries, have energy levels close to the conduction band, and the trapped electrons can be easily released into the conduction band by thermal energy. The temperature dependence of $V_{\mathrm{T}}$ was used as the sensitivity parameter for the device. The $V_{\mathrm{T}}$ shows a linear relationship with temperature in the range of 29 to $45^{\circ} \mathrm{C}$ with a temperature coefficient value of $200 \mathrm{mV} /{ }^{\circ} \mathrm{C}$, which is higher than the values reported for inorganic semiconductor-based FET temperature sensors. It was found that maintaining a stoichiometric ratio of $\mathrm{MAI}$ and $\mathrm{PbI}_{2}$ is critical to achieving a high sensitivity. The devices with the $\mathrm{PbI}_{2}$-rich and MAI-rich films exhibited much lower temperature coefficients of 12 and $100 \mathrm{mV} /{ }^{\circ} \mathrm{C}$, respectively, since unreacted $\mathrm{PbI}_{2}$ and MAI can reduce carrier traps. 

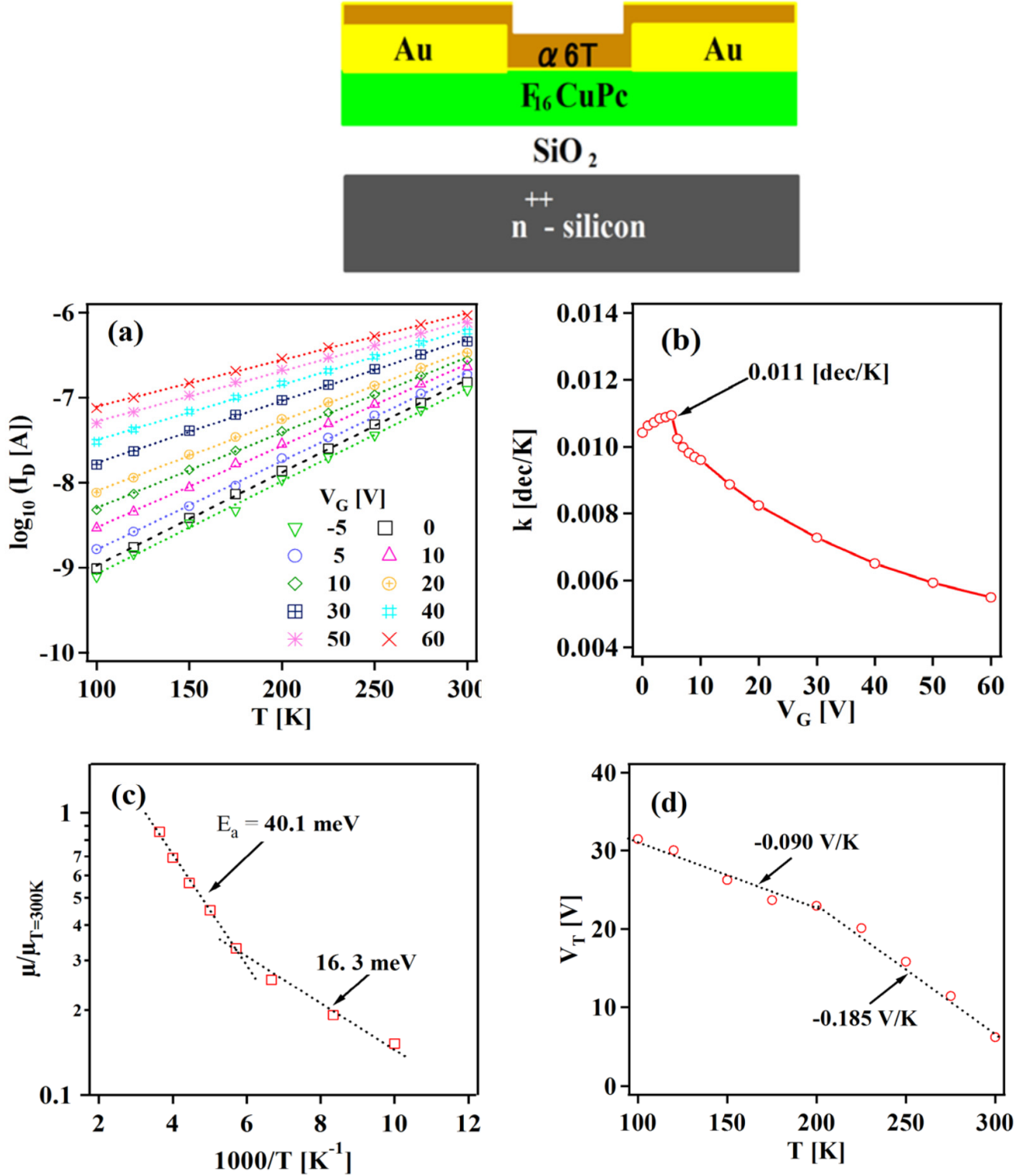

Figure 5. (a) Dependence of $\log \left(I_{\mathrm{DS}}\right)$ on the temperatures at different $V_{\mathrm{GS}}$, (b) dependence of $k$ on $V_{\mathrm{GS}}$ in $\log \left(I_{\mathrm{DS}}\right)=k T+c_{0}$ obtained from data in (a), (c) temperature dependence of $\mu$, and (d) temperature dependence of $V_{\mathrm{T}}$ of the $\alpha 6 \mathrm{~T}(20 \mathrm{~nm}) / \mathrm{F}_{16} \mathrm{CuPc}(50 \mathrm{~nm})$ OFET device in the linear regime. Reproduced with permission from [60] Scientific Research, 2016. Note: $I_{\mathrm{D}}$ and $V_{\mathrm{G}}$ in (a) are $I_{\mathrm{DS}}$ and $V_{\mathrm{GS}}$, respectively.

\subsection{OFET Dielectric Layer as Sensing Element}

Insulating polymers are often used as dielectric materials in OFETs due to their compatibility with flexible substrates and solution processibility via spin coating, casting, and printing under ambient conditions [68]. Moreover, as with the polymer semiconductors, the structure and functionality of the polymer dielectric can be tuned to meet the requirements of the device. In particular, the properties of some polymer dielectrics are more temperaturedependent than organic semiconductors, so they can be used as sensing elements for OFET temperature sensors.

The 2015 paper by Wu et al. [40] aims to solve the issue with OFET sensor sensitivity at higher temperatures. A common issue with OFET temperature sensors is that above $\sim 300 \mathrm{~K}$ the devices show limited thermal sensitivity. This design incorporates a thermoresponsive polar polymer into the dielectric layer of the DNTT-based OFET, which induces interfacial interactions to facilitate charge transport at high temperatures. Polylactide (PLA) was used 
as the polar material that serves both as a flexible substrate and as a gate dielectric for the device with both $\mathrm{n}$ - and p-type small-molecule semiconducting active layers. Specifically, three-arm stereocomplex PLA (tascPLA) was synthesized from the ring-opening polymerization of D-lactide and used for these devices. The MTR mechanism can describe the role that the dielectric plays in temperature sensing. At the interface, PLA induces multiple charge carrier traps with varying energy levels, which decreases the carrier concentration. As the temperature increases, the thermal energy can release carriers from these traps and thus modulate the $I_{\mathrm{DS}}$ response. The DNTT-tascPLA-OFET shows a much stronger response in $I_{\mathrm{DS}}$ with temperature in the range of 25 to $150{ }^{\circ} \mathrm{C}$ compared to the device using $\mathrm{SiO}_{2}$ as the dielectric (Figure 6a,b), indicating the high thermal sensitivity of PLA. The device showed excellent cycling stability at $100{ }^{\circ} \mathrm{C}$ (Figure $6 \mathrm{c}, \mathrm{d}$ ). Mobility and $V_{\mathrm{T}}$ also show high sensitivities to temperature (Figure 6e,f).
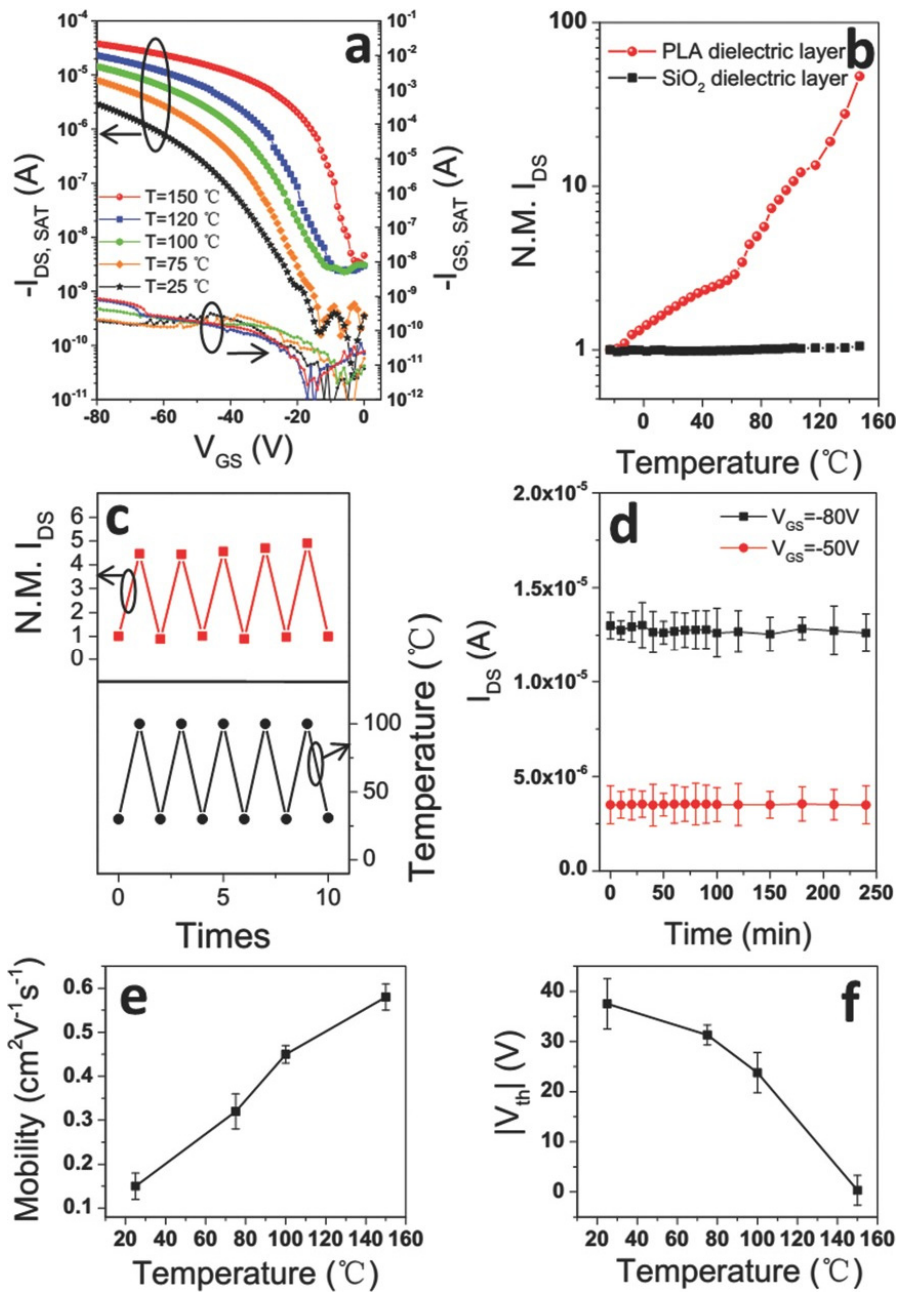

Figure 6. Temperature sensitivity of DNTT-tascPLA-OFETs: (a) transfer characteristics of DNTTtascPLA-OFET $\left(V_{\mathrm{DS}}=-60 \mathrm{~V}\right)$ at different temperatures, $(\mathbf{b})$ normalized (N.M.) $I_{\mathrm{DS}}$ at different temperatures of the OFETs with tascPLA or $\mathrm{SiO}_{2}$ dielectric layers, (c) normalized $I_{\mathrm{DS}}$ of the DNTTtascPLA-OFET measured between two temperatures of 25 and $100{ }^{\circ} \mathrm{C}$, (d) $I_{\text {DS }}$ of the tascPLA-OFETs maintained at $100{ }^{\circ} \mathrm{C}$ as a function of time at $V_{\mathrm{DS}}=-80 \mathrm{~V}$ at two different $V_{\mathrm{GS}}$, and (e) $\mu$ and (f) $V_{\mathrm{T}}$ of the DNTT-tascPLA-OFETs at different temperatures. Reproduced with permission from [40] Wiley-VCH, 2015.

Subbarao et al. used $\mathrm{CuPc}$ as the semiconducting layer in conjunction with a tri-layer dielectric system where the polar PVA layer is deposited between a layer of poly(methyl methacrylate) (PMMA) and a layer of $\mathrm{Al}_{2} \mathrm{O}_{3}$ [69]. The sensor results displayed two distinct linear trends in the ranges of 240 to $300 \mathrm{~K}$ and 300 to $370 \mathrm{~K}$ with sensitivities of $0.45 \mathrm{nA} /{ }^{\circ} \mathrm{C}$ 
and $8 \mathrm{nA} /{ }^{\circ} \mathrm{C}$, respectively. Below $300 \mathrm{~K}$ it can be assumed that the $\mathrm{VRH}$ mechanism dominates over the MTR mechanism, while above $300 \mathrm{~K}$ the opposite occurs. The device showed quite fast response and recovery times of 25 and $15 \mathrm{~s}$, respectively. The response and recovery times included the time to mechanically switch between temperatures, and the actual sensor response and recovery times are expected to be much faster [69].

Mandal et al. incorporated hexagonal barium titanate nanocrystals (h-BTNCs) as a dielectric film and pentacene as the channel layer to fabricate ultrafast, flexible OFET temperature sensor devices [70]. The perovskite $\mathrm{BaTiO}_{3}$ is a ferroelectric material with its ferroelectric property originated from the crystal structure distortion upon temperature change. The $\mathrm{BaTiO}_{3}$ film synthesized by the traditional high-temperature process is very rough, which will have a negative impact on the current at the semiconductor/dielectric interface. Furthermore, the perovskite $\mathrm{BaTiO}_{3}$ only shows ferroelectric properties at low temperatures. To circumvent these issues, the authors developed a low-temperature $\left(\sim 60^{\circ} \mathrm{C}\right)$ process to prepare h-BTNCs. Thin films of h-BTNCs with very smooth surfaces can be obtained simply by spin coating. A series of OFETs with a bilayer dielectric of h-BTNC (55 nm) on $\mathrm{Al}_{2} \mathrm{O}_{3}(15 \mathrm{~nm})$, a pentacene semiconductor layer, $\mathrm{Cu}$ source, and drain electrodes were fabricated on a thin Al-coated poly(ethylene terephthalate) (PET) substrate $(10 \mu \mathrm{m})$, where the Al layer is the gate electrode. The devices were encapsulated with a PDMS layer. The OFETs had a low operating voltage of $1.5 \mathrm{~V}$ and achieved a high mobility of $1.46 \mathrm{~cm}^{2} /(\mathrm{V} \cdot \mathrm{s})$. When the device was used as a temperature sensor, it showed a linear dependence of $I_{\mathrm{DS}}$ on temperature with a slope (sensitivity) of $20 \mathrm{nA} /{ }^{\circ} \mathrm{C}$ between 27 and $45^{\circ} \mathrm{C}$. The greatly enhanced sensitivity is mainly due to the use of the h-BTNC layer since the contributions of pentacene, and other layers are very small. The flexibility of the device was also evaluated, and the sensor maintained a stable response with a minimal level of hysteresis in the temperature range when subjected to bending with a radius of $4 \mathrm{~mm}$. The device was used to monitor the temperature changes of the air inhaled and exhaled through the nose a few $\mathrm{cm}$ from the device. Rapid response and recovery times of 24 and $51 \mathrm{~ms}$, respectively, were achieved.

Rullyani et al. reported the use of poly( $N$-isopropylacrylamide) (PNIPAM) as a thermoresponsive polymer dielectric for OFET sensors [71]. The PNIPAM layer undergoes reversible phase transitions above its lower critical solution temperature of $32{ }^{\circ} \mathrm{C}$. These transitions enhance the charge transport in the semiconducting layer (pentacene in this case) due to an improved semiconductor/dielectric interface with increasing temperature. The sensor was evaluated between 30 and $45^{\circ} \mathrm{C}$ with a sensitivity of $2.58 \mu \mathrm{A} /{ }^{\circ} \mathrm{C}$ with the $I_{\mathrm{DS}}$ being on the order of microamperes. The device is suitable for sensing the human body temperatures.

\subsection{Thermistor as Sensing Element}

As aforementioned, $I_{\mathrm{DS}}$ is a preferred parameter as an output signal of OFET temperature sensors because of its high reliability, but its temperature dependence is weak. On the other hand, $V_{\mathrm{T}}$ has strong temperature dependence, but it is affected by numerous factors in the fabrication process and the device operating environment. To solve this issue, thermistors, whose resistance changes notably with temperature, have been integrated with OFETs to make temperature sensors with a high sensitivity.

Ren et al. [42] integrated a thermistor with an OFET to improve the dependence of $I_{\mathrm{DS}}$ on temperature (Figure 7), and used dynamic range (DR) to present the sensitivity of the device. The thermistor consists of pentacene film embedded with Ag nanoparticles and two electrodes. One electrode of the thermistor is connected to the gate of the pentacene-based OTFT, so the gate bias of the OFET can be modulated by the resistance of the thermistor. Ag nanoparticles act as charge traps, so the conductivity activation energy of the thermistor film is increased to $361 \mathrm{meV}$ compared with pure pentacene $(157 \mathrm{meV})$. This results in a stronger dependence of the conductivity on the temperature of the thermistor film. 

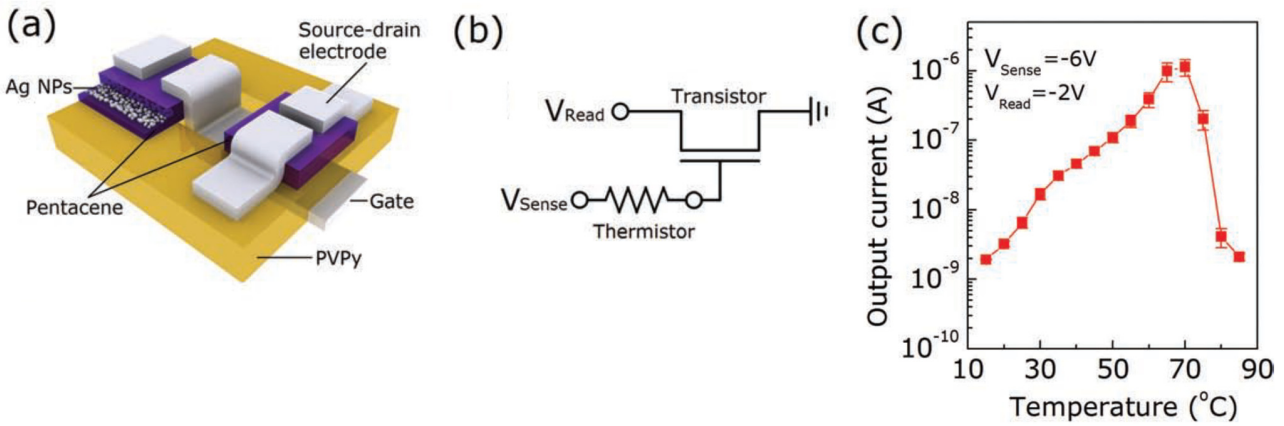

Figure 7. (a) The schematic diagram of the transistor-thermistor temperature sensor; (b) The circuit of temperature sensor; (c) $I_{\mathrm{DS}}$ response to temperature of the transistor-thermistor device. Reproduced with permission from [42] Wiley-VCH, 2013.

The integrated temperature sensor device shows almost three orders of magnitude increase in $I_{\mathrm{DS}}$ with temperature when measured between 15 and $70{ }^{\circ} \mathrm{C}$ with a measurement step of $5^{\circ} \mathrm{C}$. The sensitivity of the temperature sensor is represented by the DR, which is the ratio between the maximum and minimum changes of $I_{\mathrm{DS}}$ at a specific temperature $(T)$ with reference to the lowest temperature $\left(15^{\circ} \mathrm{C}\right)$ : $\mathrm{DR}=\Delta I_{\mathrm{T} \text { max }} / \Delta I_{\mathrm{T} \text { min }}$, where $\Delta I_{\mathrm{T}}=I_{\mathrm{T}}-I_{15}$. A higher DR implies a more sensitive device. This device had a DR of 10 bits $\left(10^{2}\right)$, which is the highest value reported among organic temperature sensors. The sensitivity of the device deteriorates rapidly above $70{ }^{\circ} \mathrm{C}$, which may be due to the evaporation of water absorbed by the polyvinylpyrrolidone (PVPy) dielectric layer at high temperatures, resulting in a decrease in capacitance.

The same research group reported a flexible low operating power $16 \times 16$ activematrix OFET temperature sensor array by adopting a similar device design [72]. A highperformance p-type semiconductor dinaphtho[2,3-b:2', $\left.3^{\prime}-f\right]$ thieno[3,2- $b$ ] thiophene (DNTT) was used as the active layer in the OFET device. An $\mathrm{Al}_{2} \mathrm{O}_{3}$ dielectric layer was used to decrease leakage current down to $\sim 50 \mathrm{pA}$. A thermistor consisting of an Ag nanoparticlesdoped pentacene film active layer was connected to the DNTT-OFET. The array fabricated on an ultrathin $(12 \mu \mathrm{m})$ PET substrate can be operated at low voltages below $4 \mathrm{~V}$. In the temperature range between 20 and $100{ }^{\circ} \mathrm{C}$, the array achieved a temperature resolution of $0.4{ }^{\circ} \mathrm{C}$ and a TCR of $-4.4 \% /{ }^{\circ} \mathrm{C}$. The device maintained its integrity after 10,000 bending cycles, and the array was able to provide excellent 2D spatial resolution. The superb flexibility and durability of the sensor array make it suitable for conformal temperature measurement of objects with irregular and varied surface geometry such as flexible electronic products and human bodies.

Temperature and pressure sensor arrays are of great interest because of their potential for artificial skin applications with spatial resolution. Yokota et al. copolymerized butyl acrylate with octadecyl acrylate P (BA-OA) and added 25\% graphite filler particles to fabricate positive temperature coefficient (PTC) thermistor sensors [73]. The PTC sensors were integrated with OFETs to create a $12 \times 12$ active matrix sensor array on a polyimide substrate, where an anodized aluminum oxide layer modified by a phosphonic acid selfassembled monolayer (SAM) was used as the gate dielectric, and a $30 \mathrm{~nm}$ DNTT layer was used as the semiconductor later in OFETs. This ultra-flexible sensor array was able to accurately measure temperature shifts after being placed between two lobes of a live rat lung, where small temperature fluctuations occur due to respiration. The array performed well between 29.8 and $37.0^{\circ} \mathrm{C}$ with minimal hysteresis $\left(1^{\circ} \mathrm{C}\right)$ and a spatial resolution of $5 \mathrm{~mm}$. Furthermore, the device had a rapid response time of $100 \mathrm{~ms}$ and remained stable for 1800 thermal cycles within the operating temperature range.

A recent work by Ishaku and Gleskova reported a temperature sensor with a DNTTOFET connected to a commercially available thermistor with a negative temperature coefficient (NTC) [74]. The OFET included a dielectric of aluminum oxide $\left(\mathrm{AlO}_{\mathrm{x}}\right)$ with an octadecylphosphonic acid ( $\left.\mathrm{C}_{18} \mathrm{PA}\right) \mathrm{SAM}$ for low voltage operation. Previous works have 
reported using $\mathrm{C}_{18} \mathrm{PA}$ to improve the $\mu_{\text {sat }}$ of charge carriers in OTFTs by inducing edge-on orientation of the semiconducting layer [75]. The integrated OFET-sensor was evaluated between 20 and $50{ }^{\circ} \mathrm{C}$ with the thermistor modulating the gate voltage. A low operational voltage of $-7 \mathrm{~V}$ and a TCR of $-2.44 \% /{ }^{\circ} \mathrm{C}$ were achieved.

Nakayama et al. reported two types of organic temperature sensing devices using a combination of $\mathrm{p}$ - and n-type semiconductors to fabricate analog-to-digital converter (ADC) OFETs [76]. The organic semiconductor layers of 3,11-didecyldinaphtho[2,3- $d: 2^{\prime}, 3^{\prime}$ $d^{\prime}$ benzo[1,2- $b: 4,5-b^{\prime}$ ]dithiophene (C10-DNBDT) and GSID 104031-1 (BASF SE) for p- and n-type OFETs, respectively, were solution processed. A unit consisting of a complementary metal oxide semiconductor (CMOS) comparator and an inverter made of the $\mathrm{p}$ - and $\mathrm{n}$ channel OFET devices is connected to a temperature sensor unit composed of two PEDOT: PSS resistors (TCR of $-0.87 \% /{ }^{\circ} \mathrm{C}$ ) and two $\mathrm{Cr} / \mathrm{Au}$ resistors (TCR: $0.064 \% /{ }^{\circ} \mathrm{C}$ ) to form a temperature detector. The temperature detector can produce a binary digital (1-bit) readout depending on whether the temperature was above a designated threshold value $\left(T_{\mathrm{th}}\right)$. The authors further fabricated a 2-bit parallel ADC composed of three comparators and one temperature sensor unit for more detailed temperature detection. The 2-bit ADC can have four output combinations, $(0,0,0),(0,0,1),(0,1,1),(1,1,1)$, corresponding to the temperature ranges of $<33{ }^{\circ} \mathrm{C}, 33-50{ }^{\circ} \mathrm{C}, 50-67^{\circ} \mathrm{C}$, and $>67^{\circ} \mathrm{C}$, respectively. Such digital signals can be easily read with common radio-frequency identification (RFID) readers.

\subsection{Other Types of Sensing Elements}

Someya et al. reported a large-area network of temperature and pressure sensors on a flexible plastic substrate using organic semiconductors [41]. The temperature sensor cell consists of an organic diode as the temperature sensing element and an OFET. The OFET device is composed of a pentacene semiconductor layer, a polyimide dielectric layer, and $\mathrm{Au}$ source, drain, and gate electrodes. The organic diode has a structure of PET/ITO/CuPc (30 nm)/PTCDI (50 nm)/Au, where PTCDI (3,4,9,10-perylenetetracarboxylic diimide) is an n-type semiconductor, forming a pn heterojunction with the p-type CuPc. The pn heterojunction layer has a much stronger temperature dependence than CuPc or PTCDI alone. Therefore, this organic diode functions as a sensing element. The magnitude of $I_{\mathrm{DS}}$ of the temperature sensor cell increases markedly from $\sim 0.4 \mu \mathrm{A}$ to $\sim 1.4 \mu \mathrm{A}$ in the range of 30 to $80{ }^{\circ} \mathrm{C}$ or $\sim 20 \mathrm{nA} /{ }^{\circ} \mathrm{C}$.

Özgün et al. reported a temperature-responsive array made by integrating pairs of organic semiconductor-based switching diodes and OFETs on a silicon-on-insulator (SOI) wafer, where pentacene was used as the semiconductor in both components [77]. When two OFETs with different sizes are driven, the voltage drop on their diodes is measured at different temperatures. The difference in voltage drop between two diodes is plotted against temperature between 27.2 and $59.0^{\circ} \mathrm{C}$. Below $35^{\circ} \mathrm{C}$, the data shows large deviations, while the rest of the data from 35.0 to $59.0^{\circ} \mathrm{C}$ shows a linear trend with a sensitivity of $16.3 \mathrm{mV} /{ }^{\circ} \mathrm{C}$. The device fabrication is relatively simple and compatible with common microfabrication processes.

Developing polymer composites is a method to improve electrical properties of polymer materials. The interactions between the polymer and the organic/inorganic material in the polymer matrix can lead to higher sensitivity and better overall performance in sensors [78]. Polymer materials can also be used as a matrix to embed active materials to take advantage of polymer properties, such as processability and stability, for organic electronic applications. In 2009, Graz et al. [79] incorporated lead titanate $\left(\mathrm{PbTiO}_{3}\right)$ nanoparticles into the matrix of ferroelectric P (VDF-TrFE). A two-step polarization process is used to polarize the foil made of this composite material, so that some areas of the $\mathrm{PbTO}_{3}$ nanoparticles and the polymer matrix have parallel polarization directions, while other areas have anti-parallel polarization directions. Areas with parallel polarization directions are pyroelectric, while areas with anti-parallel polarization directions are piezoelectric. The composite foil was laminated to amorphous silicon (a-Si) TFTs on their polyimide gate dielectric substrate in the adjacent parallel and anti-parallel polarization directions, 
respectively. The $I_{\mathrm{DS}}$ of a TFT is modulated pyro- or piezoelectrically depending on the polarization directions of the composite foil area. The device significantly reduced cross-sensitivity between the piezoelectric and pyroelectric effects and displayed a linear relationship correlated to temperature.

Sensor devices can be connected to one of the electrodes of an OFET and their response to the target analyte can be used to modulate a characteristic of the OFET device that changes the output signal of the OFET. In 2014, Cosseddu et al. introduced a temperature sensor based on an organic charge modulated field effect transistor (OCMFET) using the pyroelectric poly(vinylidene difluoride) (PVDF) [43]. The polymer film forms the dielectric layer of a parallel plate capacitor, which is connected to the floating gate of an OFET device. Temperature modulations affect the charge separation in the PVDF layer, which modulates the carrier concentration that directly correlates the $I_{\mathrm{DS}}$ response of the sensor. Calibration curves of $\Delta I_{\mathrm{DS}}-\mathrm{T}$ for this temperature sensor were established within a working range of 10 to $42{ }^{\circ} \mathrm{C}$.

Table 1 summarizes the OFET-based temperature sensors using the small-molecule materials discussed in this section organized by sensing the elements and reporting the OFET channel material, working range, output signal, and the reported sensitivity of each device.

Table 1. Summary of of small-molecule OFET temperature sensors.

\begin{tabular}{|c|c|c|c|c|c|c|}
\hline Sensor Structure & OFET Channel & Sensing Element & Working Range & Sensor Parameter & Sensitivity & Year [Ref.] \\
\hline \multicolumn{7}{|c|}{ Sensing element: OFET active layer } \\
\hline OFET & Pentacene & OFET channel & $0-80^{\circ} \mathrm{C}$ & $I_{\mathrm{DS}, \text { sub }}$ & $\sim 0.1 \mathrm{nA} /{ }^{\circ} \mathrm{C}^{1}$ & 2006 [39] \\
\hline OFET & Pentacene & OFET channel & $0-180^{\circ} \mathrm{C}$ & $I_{\mathrm{DS}, \mathrm{sub}}, V_{\mathrm{T}}$ & - & $2007[55]$ \\
\hline OFET & $\mathrm{CuPc}$ & OFET channel & $25-90{ }^{\circ} \mathrm{C}$ & $V_{\mathrm{T}}$ & $0.11 \mathrm{~V} /{ }^{\circ} \mathrm{C}$ & 2019 [59] \\
\hline OFET & $\mathrm{F}_{16} \mathrm{CuPc}$ & OFET channel & $25-90^{\circ} \mathrm{C}$ & $V_{\mathrm{T}}$ & $\begin{array}{l}-0.25 \mathrm{~V} /{ }^{\circ} \mathrm{C} \\
-0.090 \mathrm{~V} /{ }^{\circ} \mathrm{C}\end{array}$ & $2019[72]$ \\
\hline OFET & $\begin{array}{c}\alpha 6 \mathrm{~T} / \mathrm{F}_{16} \mathrm{CuPc} \\
\text { pn junction }\end{array}$ & OFET channel & $-173-27^{\circ} \mathrm{C}$ & $V_{\mathrm{T}}$ & $\begin{array}{c}\left(<-73^{\circ} \mathrm{C}\right) \\
-0.185 \mathrm{~V} /{ }^{\circ} \mathrm{C} \\
\left(>-73^{\circ} \mathrm{C}\right)\end{array}$ & $2016[60]$ \\
\hline $\begin{array}{c}\text { Organic-inorganic } \\
\text { FET }\end{array}$ & $\mathrm{MAPbI}_{3}$ & FET channel & $20-45^{\circ} \mathrm{C}$ & $V_{\mathrm{T}}$ & $-200 \mathrm{mV} /{ }^{\circ} \mathrm{C}$ & $2020[67]$ \\
\hline \multicolumn{7}{|c|}{ Sensing element: dielectric layer } \\
\hline OFET & $\begin{array}{c}\text { 6PTTP6 } \\
\text { 8-3-NTCDI } \\
\text { DNTT }\end{array}$ & $\begin{array}{l}\text { Dielectric } \\
\text { (PLA) }\end{array}$ & $-25-200{ }^{\circ} \mathrm{C}$ & $I_{\mathrm{DS}}$ & $0.29 \mu \mathrm{A} /{ }^{\circ} \mathrm{C}^{1}$ & 2015 [40] \\
\hline OFET & $\mathrm{CuPc}$ & $\begin{array}{l}\text { Dielectric } \\
\text { (PVA) }\end{array}$ & $-20-0{ }^{\circ} \mathrm{C}$ & $I_{\mathrm{DS}}$ & $\begin{array}{c}0.45 \mathrm{nA} /{ }^{\circ} \mathrm{C}(<300 \mathrm{~K}) \\
8 \mathrm{nA} /{ }^{\circ} \mathrm{C}(>300 \mathrm{~K})\end{array}$ & 2018 [69] \\
\hline OFET & Pentacene & $\begin{array}{l}\text { Dielectric } \\
\text { (h-BTNC) }\end{array}$ & $27-45^{\circ} \mathrm{C}$ & $I_{\mathrm{DS}}$ & $20 \mathrm{nA} /{ }^{\circ} \mathrm{C}$ & 2019 [70] \\
\hline OFET & Pentacene & $\begin{array}{l}\text { Dielectric } \\
\text { (PNIPAM) }\end{array}$ & $30-45^{\circ} \mathrm{C}$ & $I_{\mathrm{DS}}$ & $2.58 \mu \mathrm{A} /{ }^{\circ} \mathrm{C}$ & $2020[71]$ \\
\hline \multicolumn{7}{|c|}{ Sensing element: thermistor } \\
\hline OFET-thermistor & Pentacene & $\begin{array}{c}\text { Thermistor } \\
\text { (Pentacene/AgNPs) }\end{array}$ & $15-70{ }^{\circ} \mathrm{C}$ & $I_{\mathrm{DS}}$ & $\mathrm{DR}=10$ bits & $2013[42]$ \\
\hline OFET-thermistor & DNTT & $\begin{array}{c}\text { Thermistor } \\
\text { (Pentacene/AgNPs) }\end{array}$ & $20-100{ }^{\circ} \mathrm{C}$ & TCR & $-4.40 \% /{ }^{\circ} \mathrm{C}$ & $2016[72]$ \\
\hline OFET-thermistor & DNTT & $\begin{array}{l}\text { PTC thermistor } \\
\text { (copolymer- } \\
\text { graphite) }\end{array}$ & $29.8-37.0^{\circ} \mathrm{C}$ & $I_{\mathrm{DS}}$ or $R$ & $20 \mathrm{mK}$ & 2015 [73] \\
\hline OFET-thermistor & DNTT & $\begin{array}{l}\text { Thermistor } \\
\text { (commercial) }\end{array}$ & $20-50{ }^{\circ} \mathrm{C}$ & TCR & $-2.44 \% /{ }^{\circ} \mathrm{C}$ & $2021[74]$ \\
\hline $\begin{array}{l}\text { OFET-thermistor } \\
\text { ADC }\end{array}$ & $\begin{array}{l}\text { C10-DNBDT (p) } \\
\text { GSID 104031-1 (n) }\end{array}$ & $\begin{array}{c}\text { Thermistors } \\
\text { (PEDOT:PSS; } \\
\text { Cr/Au) }\end{array}$ & $33-67^{\circ} \mathrm{C}$ & Binary codes & - & 2016 [76] \\
\hline \multicolumn{7}{|c|}{ Sensing element: other types } \\
\hline OFET-diode & Pentacene & $\begin{array}{c}\text { Diode } \\
\text { (CuPc/PTCDI) }\end{array}$ & $30-80{ }^{\circ} \mathrm{C}$ & $I_{\mathrm{DS}}$ & $\sim 20 \mathrm{nA} /{ }^{\circ} \mathrm{C}$ & $2005[41]$ \\
\hline OFET-diode & Pentacene & $\begin{array}{l}\text { OFET\& } \\
\text { Diode }\end{array}$ & $27.2-59.0^{\circ} \mathrm{C}$ & $V_{\mathrm{DS}}$ & $16.3 \mathrm{mV} /{ }^{\circ} \mathrm{C}$ & 2013 [77] \\
\hline OFET-capacitor & Pentacene & $\begin{array}{l}\text { Capacitor } \\
\text { (polymer } \\
\text { composite) }\end{array}$ & $\sim$ r. t. & $I_{\mathrm{DS}}$ & $\sim 30 \mathrm{nA} /{ }^{\circ} \mathrm{C}^{1}$ & 2009 [79] \\
\hline OFET-capacitor & TIPS & $\begin{array}{l}\text { Pyroelectric } \\
\text { (PVDF) }\end{array}$ & $10-42{ }^{\circ} \mathrm{C}$ & $I_{\mathrm{DS}}$ & $\sim 0.14 \mu \mathrm{A} /{ }^{\circ} \mathrm{C}^{1}$ & $2014[43]$ \\
\hline
\end{tabular}

${ }^{1}$ Estimated.

\section{Polymer Semiconductor-Based OFET Temperature Sensors}

Compared to small-molecule materials, polymeric semiconductors have much better solution processability and mechanical strength and are widely used in organic electronics 
such as OFETs, organic light emitting diodes (OLEDs), organic solar cells, and various other applications [80-85].

Polythiophenes are among the earliest and most-studied polymer semiconductors for OFETs [86-89]. In 1993, Ohmori et al. fabricated Schottky gated OFET devices using poly(3-alkylthiophene)s with different alkyl side chains as the semiconducting layer for temperature sensors [90]. Poly(3-ethylthiophene) (P3ET) demonstrated the best response to temperature changes in the range of 14 to $75^{\circ} \mathrm{C}$ when measured in the saturation region. The charge carrier mobilities were evaluated to be $0.0004 \mathrm{~cm}^{2} / \mathrm{V}$ and $0.006 \mathrm{~cm}^{2} / \mathrm{V}$ at the high and low temperatures of $14{ }^{\circ} \mathrm{C}$ and $75^{\circ} \mathrm{C}$, respectively. This confirmed that the charge transport of P3ET obeys the VRH theory, where a higher temperature augments the probability of hopping transport events, leading to higher carrier mobility. Song et al. reported the use of a poly(3-hexylthiophene) (P3HT)-based OFET as a temperature sensor [91]. The P3HT film was deposited on top of a PMMA dielectric layer with a bottom ITO gate electrode. The $I_{\mathrm{DS}}$ increases linearly with temperature in the range between 25 and $100{ }^{\circ} \mathrm{C}$. The authors used the hole mobility temperature coefficient $\Delta \mu_{\mathrm{h}} / \Delta T=2.34 \times 10^{-5} \mathrm{~cm}^{2} / \mathrm{V} \cdot \mathrm{s} \cdot{ }^{\circ} \mathrm{C}$ to assess the thermal sensitivity of the device. In a 2019 study, Zhu et al. used crosslinked polystyrene-block-poly(ethylene-ran-butylene)-block-polystyrene (SEBS) as the dielectric material and PDPPFT4 or poly(isoindigo-bithiophene) (PII2T) as the semiconductor channel layer in OFETs [92]. The devices showed a linear relationship in the response of $I_{\mathrm{DS}}$ to temperature changes between 25 and $55{ }^{\circ} \mathrm{C}$. Devices with PDPPFT4 and PII2T showed TCRs of $-2.89 \% /{ }^{\circ} \mathrm{C}$ and $-4.23 \% /{ }^{\circ} \mathrm{C}$, respectively. The hysteresis effect was negligible for both sensors due to the use of the non-polar gate dielectric. The sensors remained stable after 50 cycles under a 30\% uniaxial strain, indicating their excellent stretchability.

The 2017 work from Zhao et al. developed a thermoelectric-gated transistor using $\mathrm{P} 3 \mathrm{HT}$ as the active layer for temperature sensing [93]. The architecture of the electrolytegated transistor (EGT) is shown in Figure 8a. Poly(vinylphosphonic acid-co-acrylic acid) $\mathrm{P}(\mathrm{VPA}-\mathrm{AA})$ was used as a polyanionic electrolyte insulating layer. An applied negative gate bias induces charge separation, forming two electrical double layers (EDLs) (or Helmholtz layers), where positive protons accumulated at the electrolyte/gate interface, while the negative anions accumulated at the semiconductor/electrolyte interface. The two EDLs are separated by only a few angstroms, resulting in a large capacitance. This device is then connected to the working electrode of an ionic thermoelectric supercapacitor (ITESC) containing an $\mathrm{NaOH}$-containing poly(ethyleneoxide) (PEO-NaOH) electrolyte (Figure $8 \mathrm{~b}$ ). A temperature gradient $(\Delta T)$ between the two electrodes of the ITESC causes ions to diffuse to the opposite poles, creating an open voltage ( $\left.V_{\text {thermal }}\right)$ between the two electrodes. The $V_{\text {thermal }}$ is used to bias the gate of the transistor, and thus the $I_{\mathrm{DS}}$ response is directly dependant on $\Delta T$. The thermal transconductance $\left(g_{\text {thermal }}\right)$ is defined for the ionic thermoelectric-gated transistor as $g_{\text {thermal }}=\Delta I_{\mathrm{DS}} / S \Delta T$, where $\Delta I_{\mathrm{DS}}$ is the change in $I_{\mathrm{DS}}$ caused by the temperature change $\Delta T$, and $S$ is the ionic Seebeck coefficient of PEO-NaOH. Therefore, $g_{\text {thermal }}$ can represent the thermal sensitivity of the device. The ionic Seebeck coefficient (S) of $\mathrm{PEO}-\mathrm{NaOH}$ is found to be as high as $11 \mathrm{mV} /{ }^{\circ} \mathrm{C}$, which is much higher than that of traditional thermoelectric materials $\left(\sim 100 \mu \mathrm{V} /{ }^{\circ} \mathrm{C}\right)$. Hence, higher sensitivity can be achieved for this thermoelectric-gated organic transistor compared to the devices using traditional thermoelectric materials. Interestingly, the authors found that the type of gate material used affects the transfer characteristics of the transistor. When a high work function metal $\mathrm{Cu}(4.3 \mathrm{eV})$ is used as the gate, it is easier to turn on the transistor than the device using a low-work function metal $\mathrm{Ti}(3.8 \mathrm{eV})$ as the gate. Consequently, the $\mathrm{Cu}$-gated transistor can detect a small $\Delta T$ as low as $1^{\circ} \mathrm{C}$, while the Ti-gated transistor requires a minimum $\Delta T$ of $3.8^{\circ} \mathrm{C}$ to obtain an appreciable $I_{\mathrm{DS}}$. This device displayed negligible hysteresis and fast response time (25-50 s) in the working range of 15 to $45^{\circ} \mathrm{C}$. It should be noted that the response time is rather limited by the response of the thermoelectric component, and not by the ionic thermoelectric-gated transistor. A simple resistor-load heat-gated invertor was fabricated, which can be switched around $\Delta T=0$ with only $20^{\circ} \mathrm{C}$ 
variation. A maximum gain of eight was achieved. This is the first demonstration that heat signal can be used as the input for logic circuits.

(a)

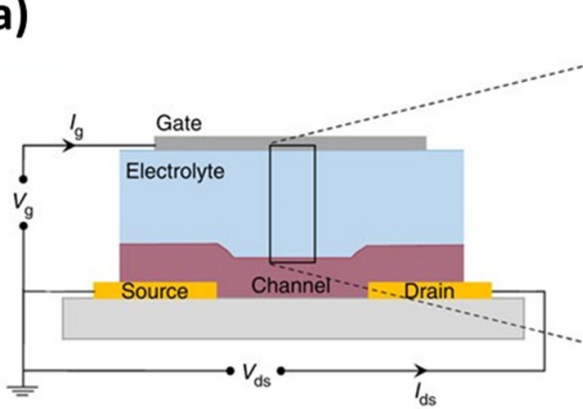

(b)

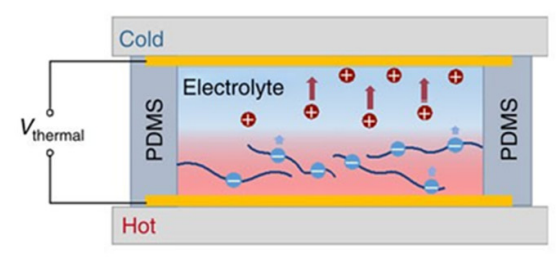

(c)

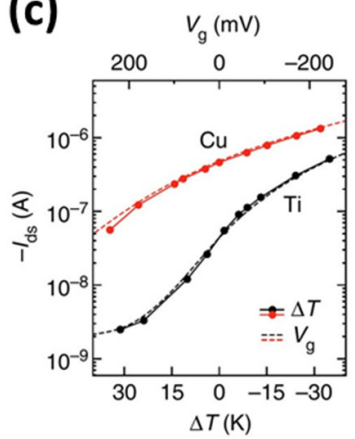

P(VPA-AA)
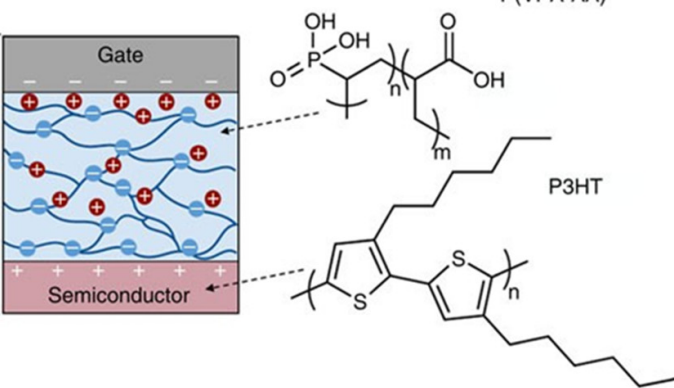

(d)

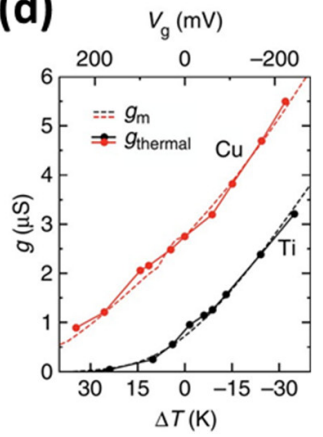

Figure 8. (a) Structure of the electrolyte-gated transistor with a negative bias applied to the gate with the formation of EDLs and the chemical structures of P3HT and P(VPA-AA); (b) Structure of the ionic thermoelectric supercapacitor (ITESC), where positive charges are $\mathrm{Na}^{+}$cations and negative charges are immobile alkoxylate and carboxylate anions; (c) The transfer characteristics; (d) Transconductance of ionic thermoelectric-gated transistors using $\mathrm{Cu}$ and $\mathrm{Ti}$ as the gate electrode versus the temperature change $(\Delta T)$. Reproduced with permission from [93] Springer Nature, 2017. Note: $V_{\mathrm{g}}$ is $V_{\mathrm{GS}}$.

Table 2 summarizes the polymer semiconductor-based OFET temperature sensors discussed in this section.

Table 2. Summary of polymer semiconductor-based OFET temperature sensors.

\begin{tabular}{|c|c|c|c|c|c|c|}
\hline Sensor Structure & OFET Channel & Sensing Element & Working Range & Sensor Parameter & Sensitivity & Year [Ref.] \\
\hline OFET & P3ET & OFET channel & $14-75^{\circ} \mathrm{C}$ & $\mu_{\mathrm{h}}$ & $\begin{array}{c}9 \times 10^{-5} \\
\left(\mathrm{~cm}^{2} / \mathrm{V} \cdot \mathrm{s}\right) /{ }^{\circ} \mathrm{C}^{1}\end{array}$ & 1993 [90] \\
\hline OFET & Р3HT & OFET channel & $25-100^{\circ} \mathrm{C}$ & $\mu_{\mathrm{h}}$ & $\begin{array}{c}2.34 \times 10^{-5} \\
\left(\mathrm{~cm}^{2} / \mathrm{V} \cdot \mathrm{s}\right) /{ }^{\circ} \mathrm{C}\end{array}$ & 2017 [91] \\
\hline OFET & PDPPFT4 & OFET channel & $25-55^{\circ} \mathrm{C}$ & TCR & $-2.89 \% /{ }^{\circ} \mathrm{C}$ & 2019 [92] \\
\hline OFET & PII2T & OFET channel & $25-55^{\circ} \mathrm{C}$ & TCR & $-4.23 \% /{ }^{\circ} \mathrm{C}$ & 2019 [92] \\
\hline OFET/capacitor & P3HT & $\begin{array}{c}\text { Capacitor } \\
(\mathrm{PEO}-\mathrm{NaOH})\end{array}$ & $15-45^{\circ} \mathrm{C}$ & $\begin{array}{c}I_{\mathrm{DS}} \\
g_{\text {thermal }}\end{array}$ & $\begin{array}{c}20 \mathrm{nA} /{ }^{\circ} \mathrm{C} \\
0.08 \mu \mathrm{S} /{ }^{\circ} \mathrm{C}^{1}\end{array}$ & 2017 [93] \\
\hline
\end{tabular}

${ }^{1}$ Estimated.

\section{Conclusions and Outlook}

Due to the high demand for a large amount of flexible, thin, lightweight, and ultralowcost sensors for applications in wearable electronics, Internet of Things, smart packaging, advanced healthcare, etc., there is growing interest in the development of sensors using organic semiconductor materials. OFET-based sensors have attracted special attention due to their ability to process on flexible substrates, for seamless integration with other components of the electronic device, and to reduce cross-sensitivity and achieve multidetection. This review presented the progress made in the development of OFET-based temperature sensors, which have the broadest and most important applications among all types of sensors. We divided the OFET-based sensors by the organic semiconductor 
channel materials into two groups: small molecules and polymers. The devices are further classified by the sensing element: OFET semiconductor channel, OFET dielectric layer, separate thermistor, and other types. Notable advances have been made in the development of OFET-based temperature sensors, which include the demonstration of high sensitivity (e.g., TCR $>2 \% /{ }^{\circ} \mathrm{C}$ ), excellent mechanical flexibility and stability, elimination of crosssensitivity, and successful integration of OFET temperature sensors with other electronic devices. These developments show the potential of OFET sensors in the above-mentioned emerging applications.

Nevertheless, the authors found that compared to the abundance of organic semiconductor materials developed for other organic electronics and the large number of studies on temperature-variable charge transports of organic semiconductors, research on OFETs as temperature sensors is significantly less. This may be because the applications of these sensors have only emerged recently, but the complicated and largely material- and devicedependent charge transport mechanism for organic semiconductors appears to be a more important factor. Specifically, the use of $V_{\mathrm{T}}, I_{\mathrm{DS}}$, or other parameters in the linear regime of the OFET as the sensor readout can provide high sensitivity. However, these parameters are extremely sensitive to the trap density in the channel material and dielectric and at their interface, which changes significantly with tiny changes in processing conditions and the environment. The $I_{\mathrm{DS}}$ in the saturation regime is a more robust output signal, but its temperature dependence is usually too weak for most organic semiconductors.

Since few organic semiconductors have been studied for OFET temperature sensors, further efforts are required to investigate more organic semiconductors in order to gain a better understanding of the relationship between the chemical structure and the temperature dependency of OFET parameters. Furthermore, material processing and device fabrication for OFET temperature sensors need to be more rigorously controlled and optimized compared to other types of applications. In addition, it is necessary to specifically design new materials with the required characteristics of OFET temperature sensors, such as high sensitivity, easy control of film quality, and less susceptibility to other stimuli in the environment. In particular, the above-mentioned temperature sensors are typically used around the room temperature or near-body temperature $\left(0\right.$ to $\left.50{ }^{\circ} \mathrm{C}\right)$. However, most of the known organic semiconductors undergo drastic changes in the charge transport mechanism, causing severe attenuation of the temperature dependence of the conductivity in this temperature range. Innovative design of organic semiconductor materials is needed to solve this problem.

Using the dielectric layer as the sensing element is an effective way to increase the sensitivity and overcome some of the issues with the devices using the channel-sensing layer. However, a high-quality and stable semiconductor channel layer is still needed to make full use of this approach. Many studies have used a separate sensing element, such as a thermistor or a capacitor, to couple to the OFET unit, which is probably the easiest and fastest way to develop OFET-based temperature sensor products. However, the temperature sensing of this type of devices is based on the two terminal sensing elements and, therefore, the devices are less intelligent than the three-terminal OFET sensors using the channel or the dielectric layer as the sensor element. For instance, they may have the cross-sensitivity issue.

Overall, there have been remarkable advances in the development of OFET temperature sensors, which gives an optimistic outlook on the manufacture of flexible and inexpensive OFET temperature sensors for practical use.

Author Contributions: Conceptualization, Y.L.; Writing-Original Draft Preparation, J.P., D.A. and J.H.L.N.; Writing-Review \& Editing, J.P., D.A., J.H.L.N. and Y.L.; Supervision, Y.L.; Funding Acquisition, Y.L. All authors have read and agreed to the published version of the manuscript.

Funding: This research was funded by the Natural Sciences and Engineering Research Council of Canada (NSERC) through the Strategic Partnership Grants for Networks (SPG-N), grant number NETGP 508526-17, and the Discovery Grants, grant number RGPIN-2016-04366. 


\section{Institutional Review Board Statement: Not applicable.}

Informed Consent Statement: Not applicable.

Data Availability Statement: Not applicable.

Conflicts of Interest: The authors declare no conflict of interest.

\section{References}

1. Klauk, H. Organic Thin-Film Transistors. Chem. Soc. Rev. 2010, 39, 2643. [CrossRef]

2. Huang, Y.; Kramer, E.J.; Heeger, A.J.; Bazan, G.C. Bulk Heterojunction Solar Cells: Morphology and Performance Relationships. Chem. Rev. 2014, 114, 7006-7043. [CrossRef]

3. van de Burgt, Y.; Melianas, A.; Keene, S.T.; Malliaras, G.; Salleo, A. Organic Electronics for Neuromorphic Computing. Nat. Electron. 2018, 1, 386-397. [CrossRef]

4. $\quad$ Lee, Y.H.; Kweon, O.Y.; Kim, H.; Yoo, J.H.; Han, S.G.; Oh, J.H. Recent Advances in Organic Sensors for Health Self-Monitoring Systems. J. Mater. Chem. C 2018, 6, 8569-8612. [CrossRef]

5. Wang, W.; Zhao, W.; Xu, H.; Liu, S.; Huang, W.; Zhao, Q. Fabrication of Ultra-Thin 2D Covalent Organic Framework Nanosheets and Their Application in Functional Electronic Devices. Coord. Chem. Rev. 2021, 429, 213616. [CrossRef]

6. Freund, R.; Zaremba, O.; Arnauts, G.; Ameloot, R.; Skorupskii, G.; Dincă, M.; Bavykina, A.; Gascon, J.; Ejsmont, A.; Goscianska, J.; et al. The Current Status of MOF and COF Applications. Angew. Chem. Int. Ed. 2021, 60, 23975-24001. [CrossRef]

7. Elkington, D.; Cooling, N.; Belcher, W.; Dastoor, P.C.; Zhou, X. Organic Thin-Film Transistor (OTFT)-Based Sensors. Electronics 2014, 3, 234-254. [CrossRef]

8. Inal, S.; Malliaras, G.G.; Rivnay, J. Benchmarking Organic Mixed Conductors for Transistors. Nat. Commun. 2017, 8, 1767. [CrossRef]

9. Lee, M.Y.; Lee, H.R.; Park, C.H.; Han, S.G.; Oh, J.H. Organic Transistor-Based Chemical Sensors for Wearable Bioelectronics. Acc. Chem. Res. 2018, 51, 2829-2838. [CrossRef]

10. Wang, N.; Yang, A.; Fu, Y.; Li, Y.; Yan, F. Functionalized Organic Thin Film Transistors for Biosensing. Acc. Chem. Res. 2019, 52, 277-287. [CrossRef]

11. Fang, X.; Zong, B.; Mao, S. Metal-Organic Framework-Based Sensors for Environmental Contaminant Sensing. Nano-Micro Lett. 2018, 10, 64. [CrossRef]

12. Urban, G.; Jachimowicz, A.; Kohl, F.; Kuttner, H.; Olcaytug, F.; Kamper, H.; Pittner, F.; Mann-Buxbaum, E.; Schalkhammer, T.; Prohaska, O.; et al. High-Resolution Thin-Film Temperature Sensor Arrays for Medical Applications. Sens. Actuators A Phys. 1990, 22, 650-654. [CrossRef]

13. Khan, Y.; Ostfeld, A.E.; Lochner, C.M.; Pierre, A.; Arias, A.C. Monitoring of Vital Signs with Flexible and Wearable Medical Devices. Adv. Mater. 2016, 28, 4373-4395. [CrossRef]

14. Mansor, H.; Shukor, M.H.A.; Meskam, S.S.; Rusli, N.Q.A.M.; Zamery, N.S. Body Temperature Measurement for Remote Health Monitoring System. In Proceedings of the 2013 IEEE International Conference on Smart Instrumentation, Measurement and Applications (ICSIMA), Kuala Lumpur, Malaysia, 25-27 November 2013; pp. 1-5.

15. Harada, S.; Kanao, K.; Yamamoto, Y.; Arie, T.; Akita, S.; Takei, K. Fully Printed Flexible Fingerprint-like Three-Axis Tactile and Slip Force and Temperature Sensors for Artificial Skin. ACS Nano 2014, 8, 12851-12857. [CrossRef]

16. Kanao, K.; Harada, S.; Yamamoto, Y.; Honda, W.; Arie, T.; Akita, S.; Takei, K. Highly Selective Flexible Tactile Strain and Temperature Sensors against Substrate Bending for an Artificial Skin. RSC Adv. 2015, 5, 30170-30174. [CrossRef]

17. Mansoor, M.; Haneef, I.; Akhtar, S.; De Luca, A.; Udrea, F. Silicon Diode Temperature Sensors-A Review of Applications. Sens. Actuators A Phys. 2015, 232, 63-74. [CrossRef]

18. Newman, C.R.; Frisbie, C.D.; da Silva Filho, D.A.; Brédas, J.-L.; Ewbank, P.C.; Mann, K.R. Introduction to Organic Thin Film Transistors and Design of N-Channel Organic Semiconductors. Chem. Mater. 2004, 16, 4436-4451. [CrossRef]

19. Zaumseil, J.; Sirringhaus, H. Electron and Ambipolar Transport in Organic Field-Effect Transistors. Chem. Rev. 2007, 107, 1296-1323. [CrossRef]

20. Schafft, H.A.; Suehle, J.S. The Measurement, Use and Interpretation of the Temperature Coefficient of Resistance of Metallizations. Solid-State Electron. 1992, 35, 403-410. [CrossRef]

21. Torsi, L.; Dodabalapur, A.; Sabbatini, L.; Zambonin, P.G. Multi-Parameter Gas Sensors Based on Organic Thin-Film-Transistors. Sens. Actuators B 2000, 67, 312-316. [CrossRef]

22. Poghossian, A.; Schultze, J.W.; Schöning, M.J. Multi-Parameter Detection of (Bio-)Chemical and Physical Quantities Using an Identical Transducer Principle. Sens. Actuators B Chem. 2003, 91, 83-91. [CrossRef]

23. Horowitz, G. Organic Field-Effect Transistors. Adv. Mater. 1998, 10, 365-377. [CrossRef]

24. Stallinga, P. Electronic Transport in Organic Materials: Comparison of Band Theory with Percolation/(Variable Range) Hopping Theory. Adv. Mater. 2011, 23, 3356-3362. [CrossRef]

25. Coropceanu, V.; Cornil, J.; da Silva Filho, D.A.; Olivier, Y.; Silbey, R.; Brédas, J.-L. Charge Transport in Organic Semiconductors. Chem. Rev. 2007, 107, 926-952. [CrossRef] 
26. Mei, Y.; Diemer, P.J.; Niazi, M.R.; Hallani, R.K.; Jarolimek, K.; Day, C.S.; Risko, C.; Anthony, J.E.; Amassian, A.; Jurchescu, O.D. Crossover from Band-like to Thermally Activated Charge Transport in Organic Transistors Due to Strain-Induced Traps. Proc. Natl. Acad. Sci. USA 2017, 114, E6739-E6748. [CrossRef]

27. Lee, J. Physical Modeling of Charge Transport in Conjugated Polymer Field-Effect Transistors. J. Phys. D Appl. Phys. 2021, 54, 143002. [CrossRef]

28. de Boer, R.W.I.; Gershenson, M.E.; Morpurgo, A.F.; Podzorov, V. Organic Single-Crystal Field-Effect Transistors. Phys. Status Solidi A 2004, 201, 1302-1331. [CrossRef]

29. Minder, N.A.; Ono, S.; Chen, Z.; Facchetti, A.; Morpurgo, A.F. Band-Like Electron Transport in Organic Transistors and Implication of the Molecular Structure for Performance Optimization. Adv. Mater. 2012, 24, 503-508. [CrossRef]

30. Yamashita, Y.; Tsurumi, J.; Hinkel, F.; Okada, Y.; Soeda, J.; Zajączkowski, W.; Baumgarten, M.; Pisula, W.; Matsui, H.; Müllen, K.; et al. Transition Between Band and Hopping Transport in Polymer Field-Effect Transistors. Adv. Mater. 2014, 26, 8169-8173. [CrossRef]

31. Rani, V.; Kumar, P.; Sharma, A.; Yadav, S.; Singh, B.; Ray, N.; Ghosh, S. Carrier Induced Hopping to Band Conduction in Pentacene. Sci. Rep. 2019, 9, 20193. [CrossRef]

32. Senanayak, S.P.; Ashar, A.Z.; Kanimozhi, C.; Patil, S.; Narayan, K.S. Room-Temperature Bandlike Transport and Hall Effect in a High-Mobility Ambipolar Polymer. Phys. Rev. B 2015, 91, 115302. [CrossRef]

33. Lee, J.; Chung, J.W.; Kim, D.H.; Lee, B.-L.; Park, J.-I.; Lee, S.; Häusermann, R.; Batlogg, B.; Lee, S.-S.; Choi, I.; et al. Thin Films of Highly Planar Semiconductor Polymers Exhibiting Band-like Transport at Room Temperature. J. Am. Chem. Soc. 2015, 137, 7990-7993. [CrossRef]

34. Schott, S.; Gann, E.; Thomsen, L.; Jung, S.; Lee, J.; McNeill, C.R.; Sirringhaus, H. Charge-Transport Anisotropy in a Uniaxially Aligned Diketopyrrolopyrrole-Based Copolymer. Adv. Mater. 2015, 27, 7356-7364. [CrossRef]

35. Yamashita, Y.; Hinkel, F.; Marszalek, T.; Zajaczkowski, W.; Pisula, W.; Baumgarten, M.; Matsui, H.; Müllen, K.; Takeya, J. Mobility Exceeding $10 \mathrm{~cm}^{2} /(\mathrm{V} \cdot \mathrm{s})$ in Donor-Acceptor Polymer Transistors with Band-like Charge Transport. Chem. Mater. 2016, 28, 420-424. [CrossRef]

36. Podzorov, V.; Menard, E.; Borissov, A.; Kiryukhin, V.; Rogers, J.A.; Gershenson, M.E. Intrinsic Charge Transport on the Surface of Organic Semiconductors. Phys. Rev. Lett. 2004, 93, 086602. [CrossRef] [PubMed]

37. Merlo, J.A.; Frisbie, C.D. Field Effect Transport and Trapping in Regioregular Polythiophene Nanofibers. J. Phys. Chem. B 2004, 108, 19169-19179. [CrossRef]

38. Hulea, I.N.; Fratini, S.; Xie, H.; Mulder, C.L.; Iossad, N.N.; Rastelli, G.; Ciuchi, S.; Morpurgo, A.F. Tunable Fröhlich Polarons in Organic Single-Crystal Transistors. Nat. Mater. 2006, 5, 982-986. [CrossRef] [PubMed]

39. Jung, S.; Ji, T.; Varadan, V.K. Point-of-Care Temperature and Respiration Monitoring Sensors for Smart Fabric Applications. Smart Mater. Struct. 2006, 15, 1872-1876. [CrossRef]

40. Wu, X.; Ma, Y.; Zhang, G.; Chu, Y.; Du, J.; Zhang, Y.; Li, Z.; Duan, Y.; Fan, Z.; Huang, J. Thermally Stable, Biocompatible, and Flexible Organic Field-Effect Transistors and Their Application in Temperature Sensing Arrays for Artificial Skin. Adv. Funct. Mater. 2015, 25, 2138-2146. [CrossRef]

41. Someya, T.; Kato, Y.; Sekitani, T.; Iba, S.; Noguchi, Y.; Murase, Y.; Kawaguchi, H.; Sakurai, T. Conformable, Flexible, Large-Area Networks of Pressure and Thermal Sensors with Organic Transistor Active Matrixes. Proc. Natl. Acad. Sci. USA 2005, 102, 12321-12325. [CrossRef]

42. Ren, X.; Chan, P.K.L.; Lu, J.; Huang, B.; Leung, D.C.W. High Dynamic Range Organic Temperature Sensor. Adv. Mater. 2013, 25, 1291-1295. [CrossRef]

43. Cosseddu, P.; Viola, F.; Lai, S.; Raffo, L.; Bonfiglio, A. A Temperature Transducer Based on a Low-Voltage Organic Thin-Film Transistor Detecting Pyroelectric Effect. IEEE Electron Device Lett. 2014, 35, 1296-1298. [CrossRef]

44. Yang, S.Y.; Kim, S.H.; Shin, K.; Jeon, H.; Park, C.E. Low-Voltage Pentacene Field-Effect Transistors with Ultrathin Polymer Gate Dielectrics. Appl. Phys. Lett. 2006, 88, 173507. [CrossRef]

45. Yamamoto, T.; Takimiya, K. Facile Synthesis of Highly $\pi$-Extended Heteroarenes, Dinaphtho[2,3- $\left.b: 2^{\prime}, 3^{\prime}-f\right]$ Chalcogenopheno[3,2b] Chalcogenophenes, and Their Application to Field-Effect Transistors. J. Am. Chem. Soc. 2007, 129, 2224-2225. [CrossRef]

46. Takimiya, K.; Shinamura, S.; Osaka, I.; Miyazaki, E. Thienoacene-Based Organic Semiconductors. Adv. Mater. 2011, 23, 4347-4370. [CrossRef] [PubMed]

47. Quinn, J.T.E.; Zhu, J.; Li, X.; Wang, J.; Li, Y. Recent Progress in the Development of N-Type Organic Semiconductors for Organic Field Effect Transistors. J. Mater. Chem. C 2017, 5, 8654-8681. [CrossRef]

48. Lin, P.; Yan, F. Organic Thin-Film Transistors for Chemical and Biological Sensing. Adv. Mater. 2012, 24, 34-51. [CrossRef]

49. Li, H.; Shi, W.; Song, J.; Jang, H.-J.; Dailey, J.; Yu, J.; Katz, H.E. Chemical and Biomolecule Sensing with Organic Field-Effect Transistors. Chem. Rev. 2019, 119, 3-35. [CrossRef]

50. Yuvaraja, S.; Nawaz, A.; Liu, Q.; Dubal, D.; Surya, S.G.; Salama, K.N.; Sonar, P. Organic Field-Effect Transistor-Based Flexible Sensors. Chem. Soc. Rev. 2020, 49, 3423-3460. [CrossRef]

51. Baeg, K.-J.; Noh, Y.-Y.; Ghim, J.; Kang, S.-J.; Lee, H.; Kim, D.-Y. Organic Non-Volatile Memory Based on Pentacene Field-Effect Transistors Using a Polymeric Gate Electret. Adv. Mater. 2006, 18, 3179-3183. [CrossRef]

52. Schroeder, R.; Majewski, L.A.; Grell, M. A Study of the Threshold Voltage in Pentacene Organic Field-Effect Transistors. Appl. Phys. Lett. 2003, 83, 3201-3203. [CrossRef] 
53. Shi, W.; Yu, J.; Katz, H.E. Sensitive and Selective Pentacene-Guanine Field-Effect Transistor Sensing of Nitrogen Dioxide and Interferent Vapor Analytes. Sens. Actuators B Chem. 2018, 254, 940-948. [CrossRef]

54. Wang, Y.; Kang, L.; Liu, Z.; Wan, Z.; Yin, J.; Gao, X.; Xia, Y.; Liu, Z. Enhancement of Memory Properties of Pentacene Field-Effect Transistor by the Reconstruction of an Inner Vertical Electric Field with an n-Type Semiconductor Interlayer. ACS Appl. Mater. Interfaces 2021, 13, 13452-13458. [CrossRef] [PubMed]

55. Jung, S.; Ji, T.; Varadan, V.K. Temperature Sensor Using Thermal Transport Properties in the Subthreshold Regime of an Organic Thin Film Transistor. Appl. Phys. Lett. 2007, 90, 062105. [CrossRef]

56. Kawakami, D.; Yasutake, Y.; Nishizawa, H.; Majima, Y. Bias Stress Induced Threshold Voltage Shift in Pentacene Thin-Film Transistors. Jpn. J. Appl. Phys. 2006, 45, L1127-L1129. [CrossRef]

57. Kwak, T.H.; Kang, H.S.; Kim, K.; Cho, M.Y.; Lee, J.W.; Joo, J. Copper-Phthalocyanine Based Organic Thin Film Transistor. In Proceedings of the 2006 IEEE Nanotechnology Materials and Devices Conference, Gyeongju, Korea, 22-25 October 2006; pp. 630-631.

58. Ye, R.; Baba, M.; Ohishi, Y.; Mori, K.; Suzuki, K. On the Correlation between Morphology and Electronic Properties of Fluorinated Copper Phthalocyanine ( $\left.\mathrm{F}_{16} \mathrm{CuPc}\right)$ Thin Films. Mol. Cryst. Liq. Cryst. 2006, 444, 203-210. [CrossRef]

59. Boileau, N.T.; Melville, O.A.; Mirka, B.; Cranston, R.; Lessard, B.H. P and N Type Copper Phthalocyanines as Effective Semiconductors in Organic Thin-Film Transistor Based DNA Biosensors at Elevated Temperatures. RSC Adv. 2019, 9, 2133-2142. [CrossRef]

60. Ye, R.; Ohta, K.; Baba, M. Temperature Dependence of Electrical Properties of Organic Thin Film Transistors Based on Pn Heterojuction and Their Applications in Temperature Sensors. J. Comput. Commun. 2016, 4, 10-15. [CrossRef]

61. Ye, R.; Baba, M.; Oishi, Y.; Mori, K.; Suzuki, K. Air-Stable Ambipolar Organic Thin-Film Transistors Based on an Organic Homostructure. Appl. Phys. Lett. 2005, 86, 253505. [CrossRef]

62. Ye, R.; Baba, M.; Suzuki, K.; Mori, K. Improved Performance of Fluorinated Copper Phthalocyanine Thin Film Transistors Using an Organic Pn Junction: Effect of Copper Phthalocyanine Film Thickness. Thin Solid Film. 2009, 517, 3001-3004. [CrossRef]

63. Wang, J.; Wang, H.; Yan, X.; Huang, H.; Yan, D. Organic Heterojunction and Its Application for Double Channel Field-Effect Transistors. Appl. Phys. Lett. 2005, 87, 093507. [CrossRef]

64. Xiang, L.; Ying, J.; Han, J.; Zhang, L.; Wang, W. High Reliable and Stable Organic Field-Effect Transistor Nonvolatile Memory with a Poly(4-Vinyl Phenol) Charge Trapping Layer Based on a Pn-Heterojunction Active Layer. Appl. Phys. Lett. 2016, 108, 173301. [CrossRef]

65. Yu, S.H.; Kang, B.; An, G.; Kim, B.; Lee, M.H.; Kang, M.S.; Kim, H.; Lee, J.H.; Lee, S.; Cho, K.; et al. Pn-Heterojunction Effects of Perylene Tetracarboxylic Diimide Derivatives on Pentacene Field-Effect Transistor. ACS Appl. Mater. Interfaces 2015, 7 , 2025-2031. [CrossRef] [PubMed]

66. Ye, R.; Ohta, K.; Baba, M. In-Situ Study of Pn-Heterojunction Interface States in Organic Thin Film Transistors. Thin Solid Film. 2014, 554, 137-140. [CrossRef]

67. Haque, F.; Lim, S.; Lee, S.; Park, Y.; Mativenga, M. Highly Sensitive and Ambient Air-Processed Hybrid Perovskite TFT Temperature Sensor. IEEE Electron Device Lett. 2020, 41, 1086-1089. [CrossRef]

68. Shao, M.; He, Y.; Hong, K.; Rouleau, C.M.; Geohegan, D.B.; Xiao, K. A Water-Soluble Polythiophene for Organic Field-Effect Transistors. Polym. Chem. 2013, 4, 5270. [CrossRef]

69. Subbarao, N.V.V.; Mandal, S.; Gedda, M.; Iyer, P.K.; Goswami, D.K. Effect of Temperature on Hysteresis of Dipolar Dielectric Layer Based Organic Field-Effect Transistors: A Temperature Sensing Mechanism. Sens. Actuators A Phys. 2018, 269, 491-499. [CrossRef]

70. Mandal, S.; Banerjee, M.; Roy, S.; Mandal, A.; Ghosh, A.; Satpati, B.; Goswami, D.K. Organic Field-Effect Transistor-Based Ultrafast, Flexible, Physiological-Temperature Sensors with Hexagonal Barium Titanate Nanocrystals in Amorphous Matrix as Sensing Material. ACS Appl. Mater. Interfaces 2019, 11, 4193-4202. [CrossRef]

71. Rullyani, C.; Singh, M.; Li, S.-H.; Sung, C.-F.; Lin, H.-C.; Chu, C.-W. Stimuli-Responsive Polymer as Gate Dielectric for Organic Transistor Sensors. Org. Electron. 2020, 85, 105818. [CrossRef]

72. Ren, X.; Pei, K.; Peng, B.; Zhang, Z.; Wang, Z.; Wang, X.; Chan, P.K.L. A Low-Operating-Power and Flexible Active-Matrix Organic-Transistor Temperature-Sensor Array. Adv. Mater. 2016, 28, 4832-4838. [CrossRef] [PubMed]

73. Yokota, T.; Inoue, Y.; Terakawa, Y.; Reeder, J.; Kaltenbrunner, M.; Ware, T.; Yang, K.; Mabuchi, K.; Murakawa, T.; Sekino, M.; et al. Ultraflexible, Large-Area, Physiological Temperature Sensors for Multipoint Measurements. Proc. Natl. Acad. Sci. USA 2015, 112 14533-14538. [CrossRef]

74. Ishaku, A.A.; Gleskova, H. Potential of Low-Voltage Organic Transistors with High on-State Drain Current for Temperature Sensor Development. Org. Electron. 2021, 93, 106152. [CrossRef]

75. Jang, S.; Son, D.; Hwang, S.; Kang, M.; Lee, S.-K.; Jeon, D.-Y.; Bae, S.; Lee, S.H.; Lee, D.S.; Kim, T.-W. Hybrid Dielectrics Composed of Al2O3 and Phosphonic Acid Self-Assembled Monolayers for Performance Improvement in Low Voltage Organic Field Effect Transistors. Nano Converg. 2018, 5, 20. [CrossRef] [PubMed]

76. Nakayama, K.; Cha, B.-S.; Kanaoka, Y.; Isahaya, N.; Omori, M.; Uno, M.; Takeya, J. Organic Temperature Sensors and Organic Analog-to-Digital Converters Based on p-Type and n-Type Organic Transistors. Org. Electron. 2016, 36, 148-152. [CrossRef] 
77. Ozgun, R.; Katz, H.E.; Andreou, A.G. Organic Diode Implementations in Configurable Architectures and Temperature Sensors. In Proceedings of the 2013 Microsystems for Measurement and Instrumentation: Fulfilling the Promise (MAMNA), Gaithersburg, MD, USA, 14 May 2013; pp. 24-27.

78. Dudhe, R.S.; Sinha, J.; Kumar, A.; Rao, V.R. Polymer Composite-Based OFET Sensor with Improved Sensitivity towards Nitro Based Explosive Vapors. Sens. Actuators B Chem. 2010, 148, 158-165. [CrossRef]

79. Graz, I.; Krause, M.; Bauer-Gogonea, S.; Bauer, S.; Lacour, S.P.; Ploss, B.; Zirkl, M.; Stadlober, B.; Wagner, S. Flexible Active-Matrix Cells with Selectively Poled Bifunctional Polymer-Ceramic Nanocomposite for Pressure and Temperature Sensing Skin. J. Appl. Phys. 2009, 106, 034503. [CrossRef]

80. Guo, X.; Baumgarten, M.; Müllen, K. Designing $\pi$-Conjugated Polymers for Organic Electronics. Prog. Polym. Sci. 2013, 38, 1832-1908. [CrossRef]

81. Zhou, H.; Yang, L.; You, W. Rational Design of High Performance Conjugated Polymers for Organic Solar Cells. Macromolecules 2012, 45, 607-632. [CrossRef]

82. Li, W.; Hendriks, K.H.; Wienk, M.M.; Janssen, R.A.J. Diketopyrrolopyrrole Polymers for Organic Solar Cells. Acc. Chem. Res. 2016, 49, 78-85. [CrossRef]

83. Sekine, C.; Tsubata, Y.; Yamada, T.; Kitano, M.; Doi, S. Recent Progress of High Performance Polymer OLED and OPV Materials for Organic Printed Electronics. Sci. Technol. Adv. Mater. 2014, 15, 034203. [CrossRef]

84. Pivrikas, A.; Sariciftci, N.S.; Juška, G.; Österbacka, R. A Review of Charge Transport and Recombination in Polymer/Fullerene Organic Solar Cells. Prog. Photovolt. Res. Appl. 2007, 15, 677-696. [CrossRef]

85. Yeh, N.; Yeh, P. Organic Solar Cells: Their Developments and Potentials. Renew. Sustain. Energy Rev. 2013, 21, 421-431. [CrossRef]

86. Sirringhaus, H.; Brown, P.J.; Friend, R.H.; Nielsen, M.M.; Bechgaard, K.; Langeveld-Voss, B.M.W.; Spiering, A.J.H.; Janssen, R.A.J.; Meijer, E.W.; Herwig, P.; et al. Two-Dimensional Charge Transport in Self-Organized, High-Mobility Conjugated Polymers. Nature 1999, 401, 685-688. [CrossRef]

87. Ong, B.S.; Wu, Y.; Liu, P.; Gardner, S. High-Performance Semiconducting Polythiophenes for Organic Thin-Film Transistors. J. Am. Chem. Soc. 2004, 126, 3378-3379. [CrossRef]

88. Ong, B.S.; Wu, Y.; Li, Y.; Liu, P.; Pan, H. Thiophene Polymer Semiconductors for Organic Thin-Film Transistors. Chem. Eur. J. 2008 14, 4766-4778. [CrossRef] [PubMed]

89. McCulloch, I.; Heeney, M.; Bailey, C.; Genevicius, K.; MacDonald, I.; Shkunov, M.; Sparrowe, D.; Tierney, S.; Wagner, R.; Zhang, W.; et al Liquid-Crystalline Semiconducting Polymers with High Charge-Carrier Mobility. Nat. Mater. 2006, 5, 328-333. [CrossRef] [PubMed]

90. Ohmori, Y.; Muro, K.; Yoshino, K. Gas-Sensitive and Temperature-Dependent Schottky Gated Field Effect Transistors Utilizing Poly(3-Alkylthiophene)s. Synth. Met. 1993, 57, 4111-4116. [CrossRef]

91. Song, M.; Seo, J.; Kim, H.; Kim, Y. Flexible Thermal Sensors Based on Organic Field-Effect Transistors with Polymeric Channel/Gate-Insulating and Light-Blocking Layers. ACS Omega 2017, 2, 4065-4070. [CrossRef]

92. Zhu, C.; Wu, H.-C.; Nyikayaramba, G.; Bao, Z.; Murmann, B. Intrinsically Stretchable Temperature Sensor Based on Organic Thin-Film Transistors. IEEE Electron Device Lett. 2019, 40, 1630-1633. [CrossRef]

93. Zhao, D.; Fabiano, S.; Berggren, M.; Crispin, X. Ionic Thermoelectric Gating Organic Transistors. Nat. Commun. 2017, 8, 14214. [CrossRef] [PubMed] 